\title{
Surface-Water Quality-Assurance Plan for the Wisconsin District of the U.S. Geological Survey, Water Resources Division
}

\section{By H.S. Garn}

U.S. GEOLOGICAL SURVEY

Open-File Report 02-30

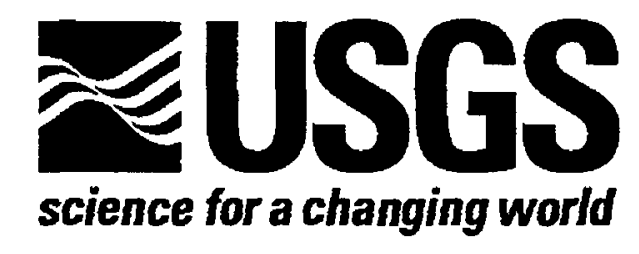




\title{
U.S. DEPARTMENT OF THE INTERIOR \\ Gale A. Norton, Secretary
}

\author{
U.S. GEOLOGICAL SURVEY \\ Charles G. Groat, Director
}

The use of firm, trade, and brand names in this report is for identification purposes only and does not constitute endorsement by the U.S. Government.

For additional information write to:

District Chief

U.S. Geological Survey

8505 Research Way

Middleton, WI 53562-3586
Copies of this report can be purchased from:

U.S. Geological Survey

Branch of Information Services

Box 25286

Denver, CO 80225-0286 


\section{CONTENTS}

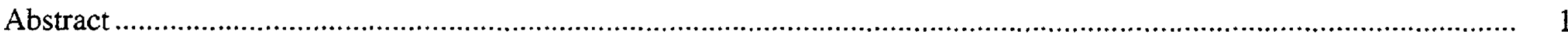

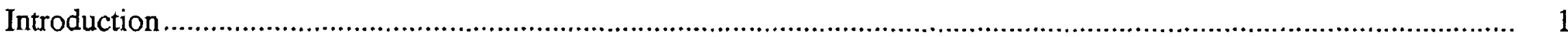

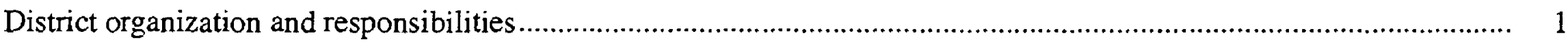

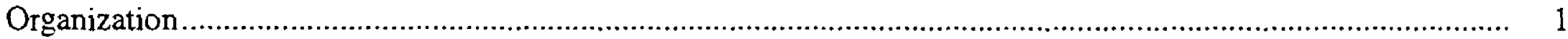

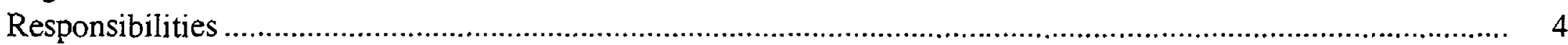

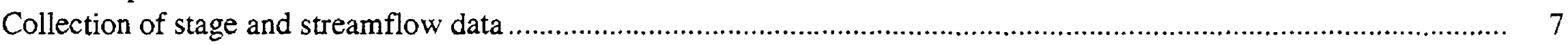

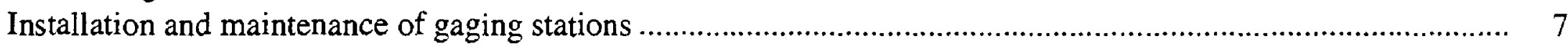

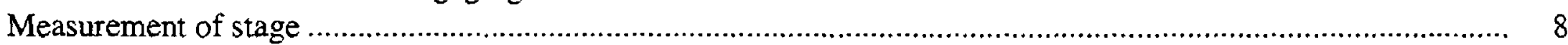

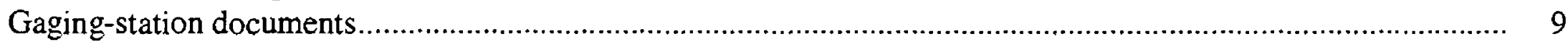

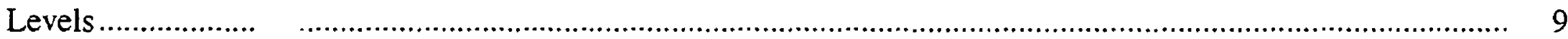

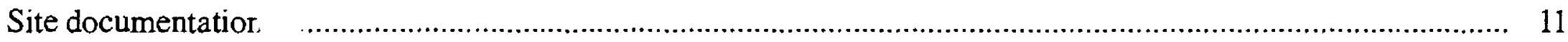

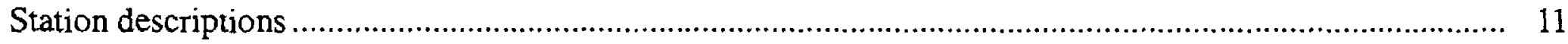

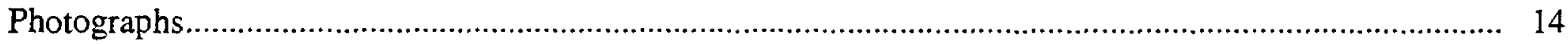

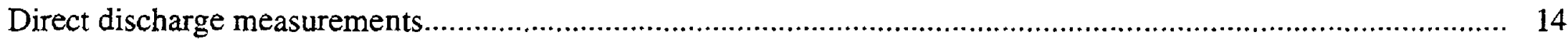

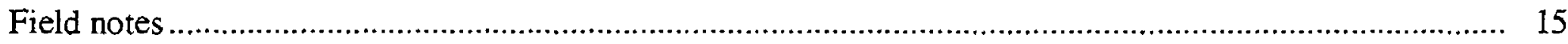

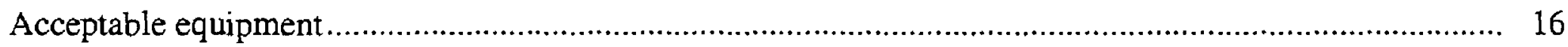

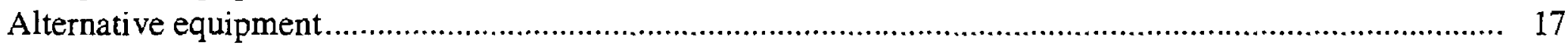

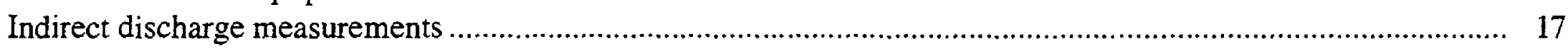

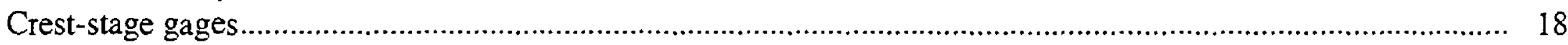

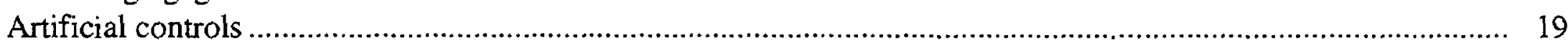

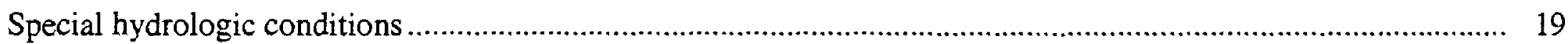

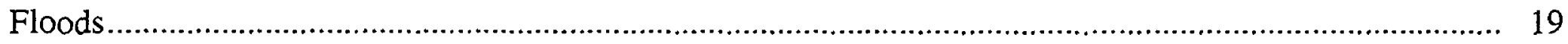

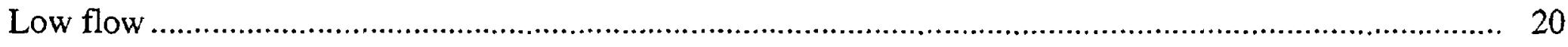

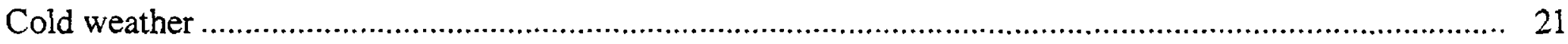

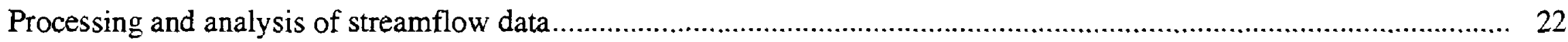

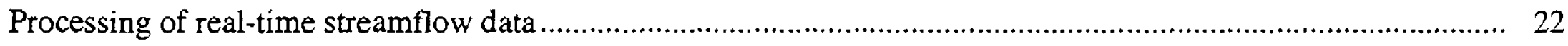

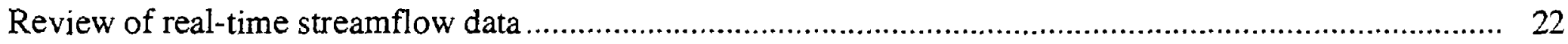

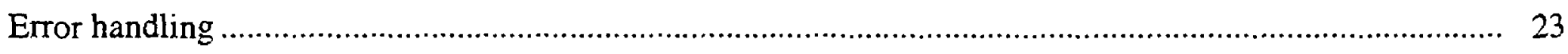

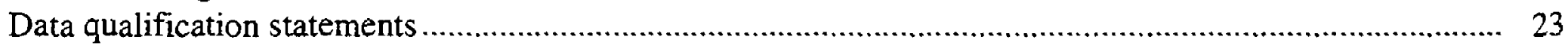

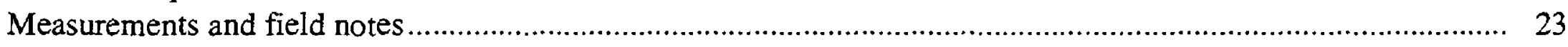

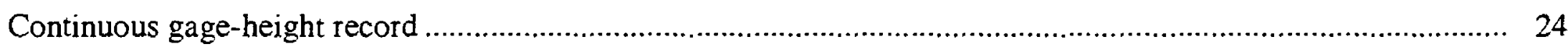

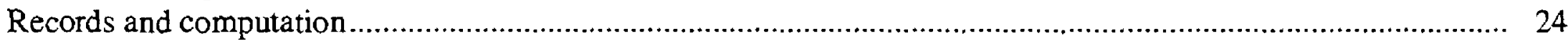

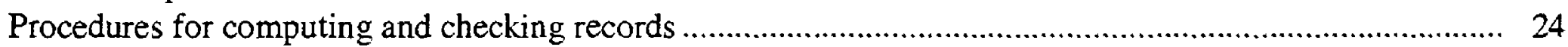

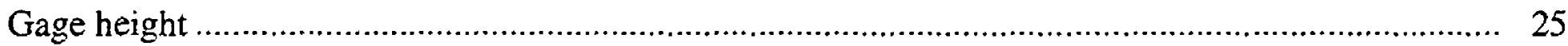

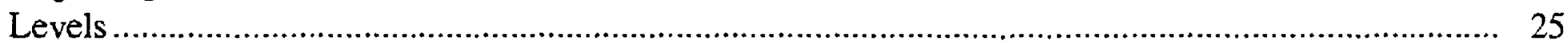

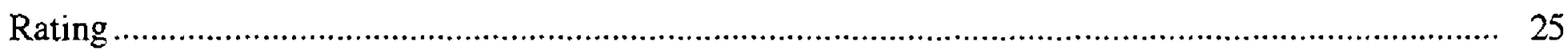

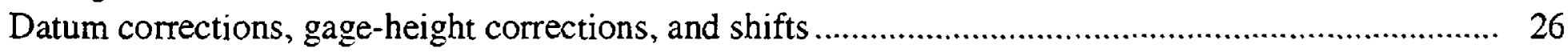

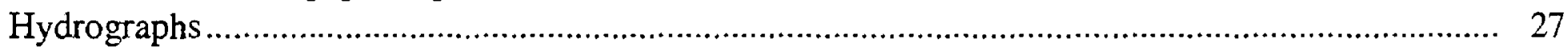

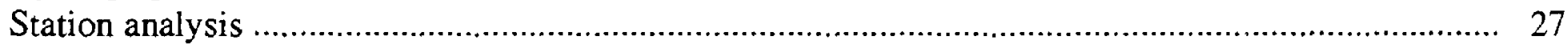

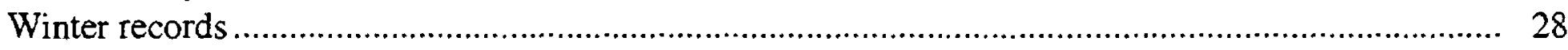

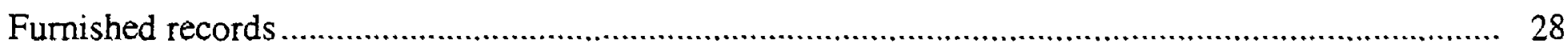

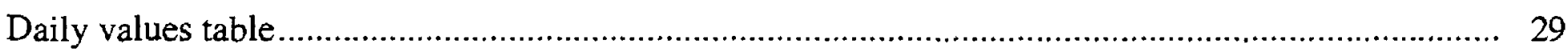

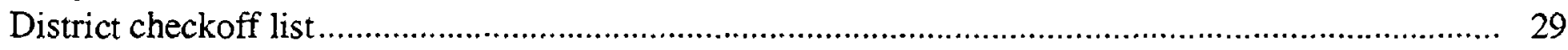

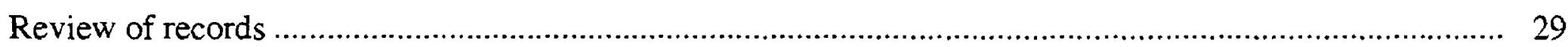

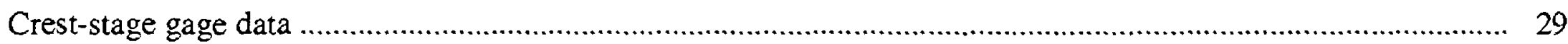

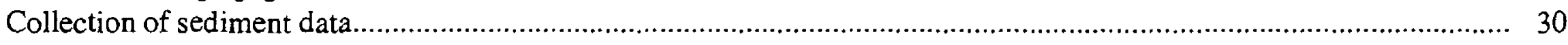

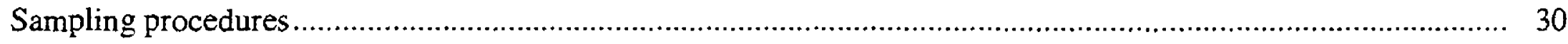

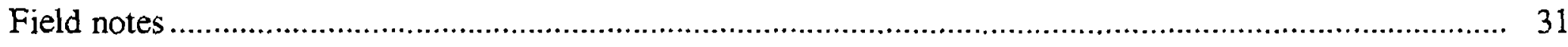

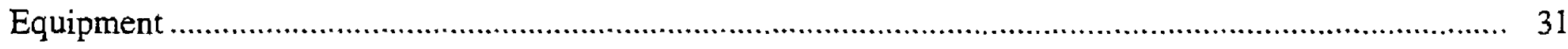

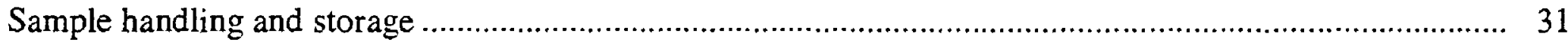

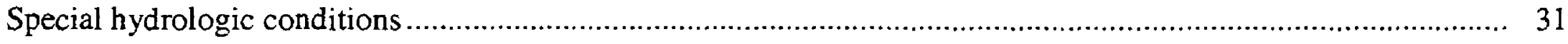

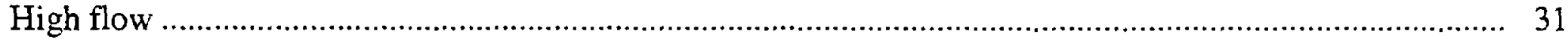

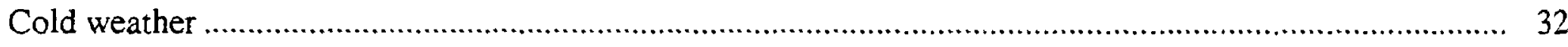




\section{CONTENTS-Continued}

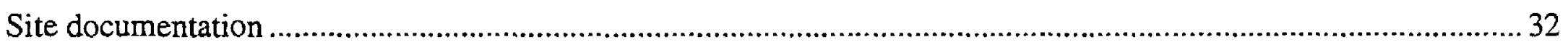

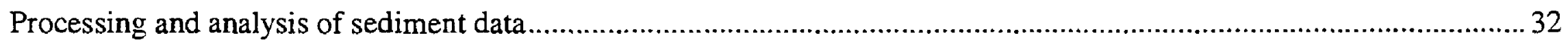

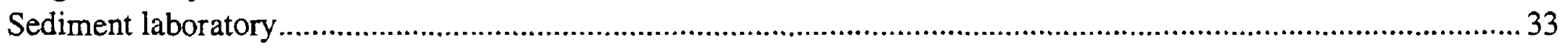

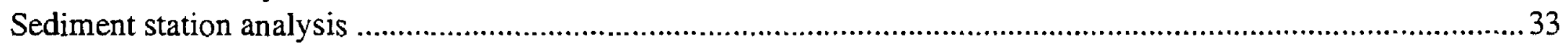

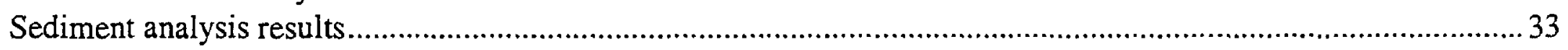

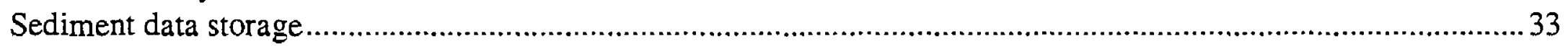

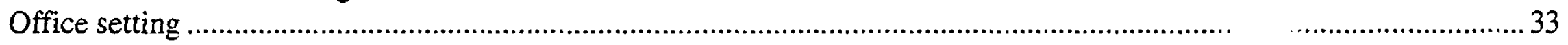

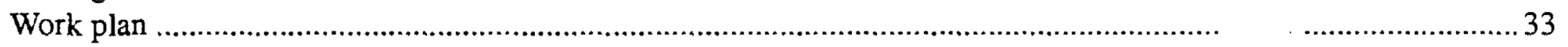

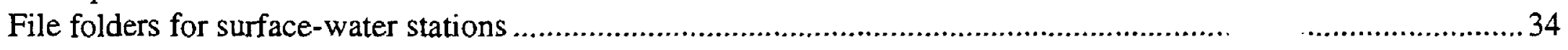

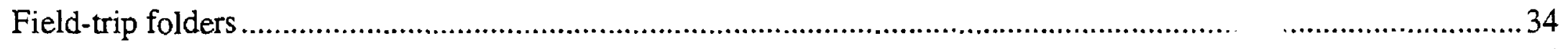

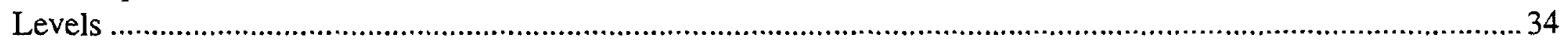

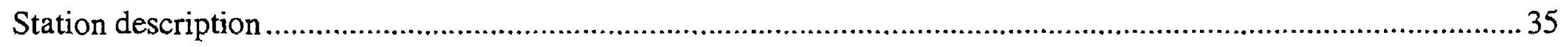

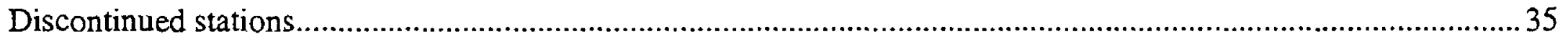

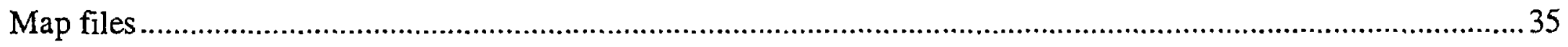

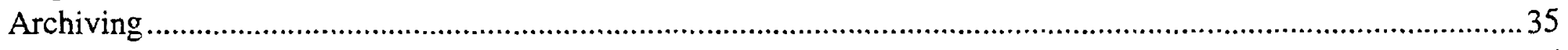

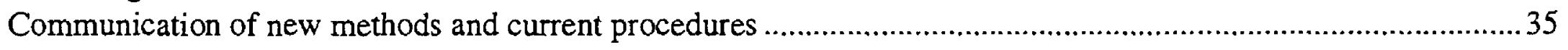

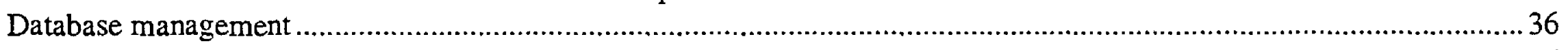

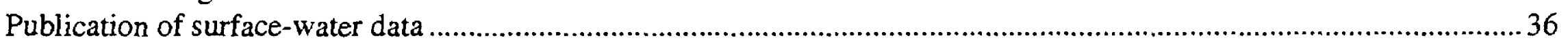

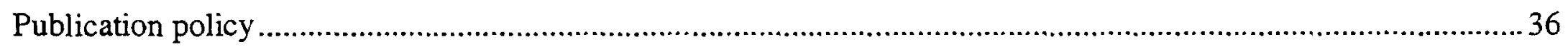

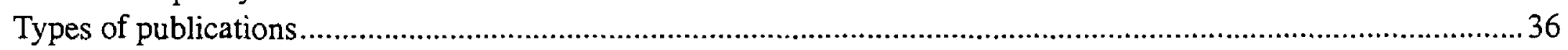

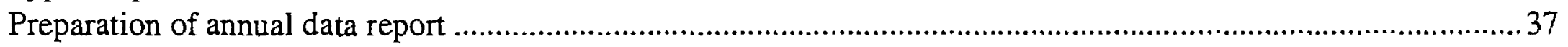

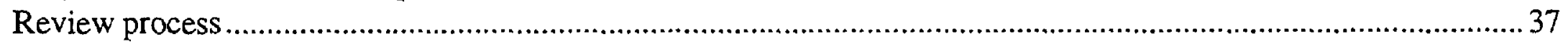

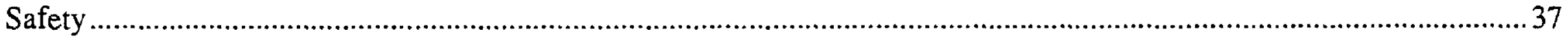

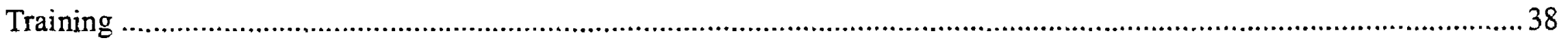

Summary

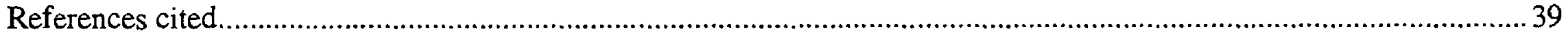

Appendixes:

1. Water Resources Division, Office of Surface Water, and Office of Water Quality memorandums .........................42

2. Computer procedures for processing real-time data, by W.R. Krug ..............................................................44

\section{FIGURES}

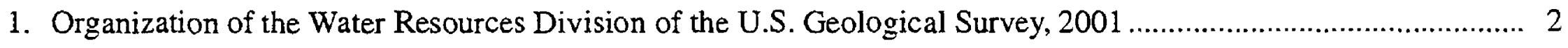

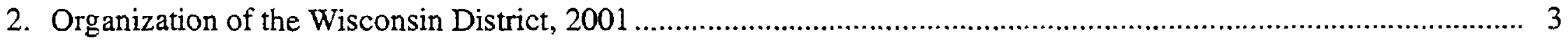

\section{Other Abbreviations Used in this Report:}

$\begin{array}{ll}\text { ADCP } & \text { Acoustic Doppler Current Profiler } \\ \text { AVM } & \text { Acoustic Velocity Meter } \\ \text { CBR } & \text { Collection of Basic Records } \\ \text { CSG } & \text { Crest-stage gage } \\ \text { HSDS } & \text { Hydrologic Studies and Data Section } \\ \text { OSW } & \text { Office of Surface Water, U.S. Geological Survey } \\ \text { QA } & \text { Quality assurance } \\ \text { QC } & \text { Quality control } \\ \text { SW } & \text { Surface water } \\ \text { WRD } & \text { Water Resources Division }\end{array}$

Sea level: In this report, "sea level" refers to the National Geodetic Vertical Datum of 1929 (NGVD of 1929)— geodetic datum derived from a general adjustment of the first-order level nets of both the United States and Canada, formerly called Sea Level Datum of 1929. 


\title{
Surface-Water Quality-Assurance Plan for the Wisconsin District of the U.S. Geological Survey, Water Resources Division
}

\author{
By H.S. Garn
}

\begin{abstract}
This surface-water :ality-assurance plan documents the standards, policies, and procedures used by the Wisconsin District of the U.S. Geological Survey, Water Resources Division, for activities related to the collection, processing, storage, analysis, management, and publication of surface-water data. The roles and responsibilities of District personnel in following these policies and procedures including those related to safety and training are presented.
\end{abstract}

\section{INTRODUCTION}

The U.S. Geological Survey (USGS) was established by an act of Congress on March 3, 1879, as a permanent Federal agency to perform the systematic and scientific "classification of the public lands, and examination of the geologic structure, mineral resources, and products of the national domain." Surface-water activities in the Wisconsin District are part of the Water Resources Division's (WRD; fig. 1) overall mission of appraising the Nation's water resources. Surface-water information, including streamflow, stage, and sediment data, are used at the Federal, State, and local levels for resource planning and management. The availability of timely, accurate, and reliable water data are critical to the management of surface waters within the State and the planning and design of water-resources projects.

The purpose of this District surface-water qualityassurance plan (QA plan) is to document the standards, policies, and procedures used by the Wisconsin District for activities related to the collection, processing, storage, analysis, and publication of surface-water data. This plan identifies responsibilities for ensuring that stated policies and procedures are carried out. The plan also serves as a guide for all District personnel involved in surface-water activities and as a resource for related memorandums, publications, and other literature that describe associated techniques and requirements in more detail. This QA Plan will be reviewed as needed for any future updates so that responsibilities and meth- odologies are kept current and ongoing procedural improvements are documented.

The scope of this plan includes discussions of the policies and procedures followed by this District for the collection, processing, analysis, storage, and publication of surface-water data. Specific types of surfacewater data include stage, reservoir storage, streamflow, sediment, and basin characteristics. In addition, issues related to the management of the computer database and employee safety and training are presented. Although procedures and products of interpretive projects are subject to the criteria presented in this report, individual interpretive projects are required to have a separate and complete quality-assurance plan.

\section{DISTRICT ORGANIZATION AND RESPONSIBILITIES}

Quality assurance (QA) is an active process. Achieving and maintaining standards for surface-water data are accomplished by specific actions carried out by specific persons. Clear and specific statements of responsibilities promote an understanding of each person's duties in the overall process of assuring surfacewater data quality.

\section{Organization}

The Wisconsin District is organized into operational sections and support units, each operational section is organized into topical work teams (fig. 2). The operational sections include the Environmental Studies Section (ESS) and the Hydrologic Studies and Data Section (HSDS), which largely conducts the surfacewater program in the District. The support units include the Administrative Unit, the Computer Applications Unit, and the Publications Unit. Three field offices in Middleton (south), Merrill (northeast), and Rice Lake (northwest) are organized under HSDS. Individual personnel are assigned as discipline specialists and management advisors. 


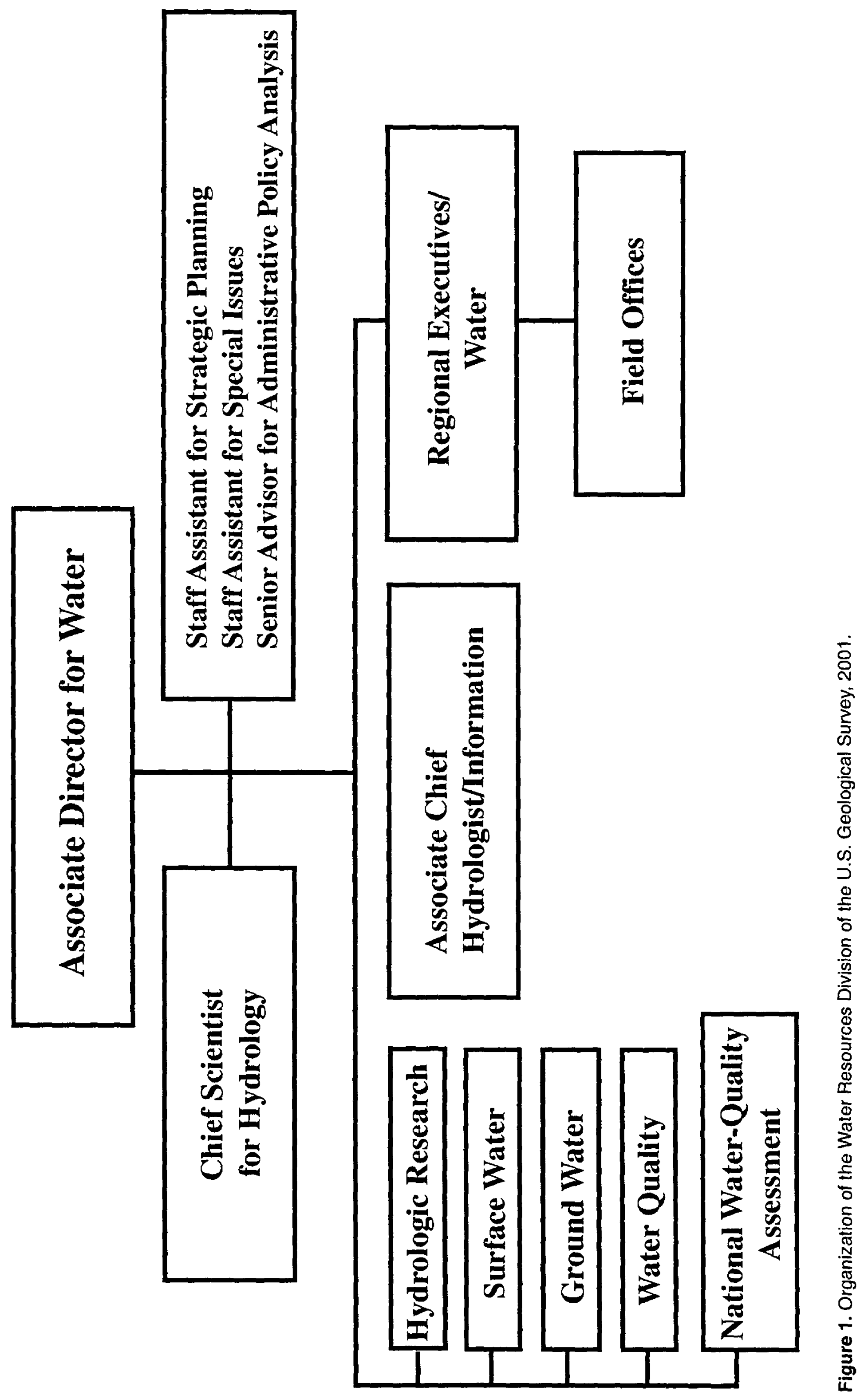




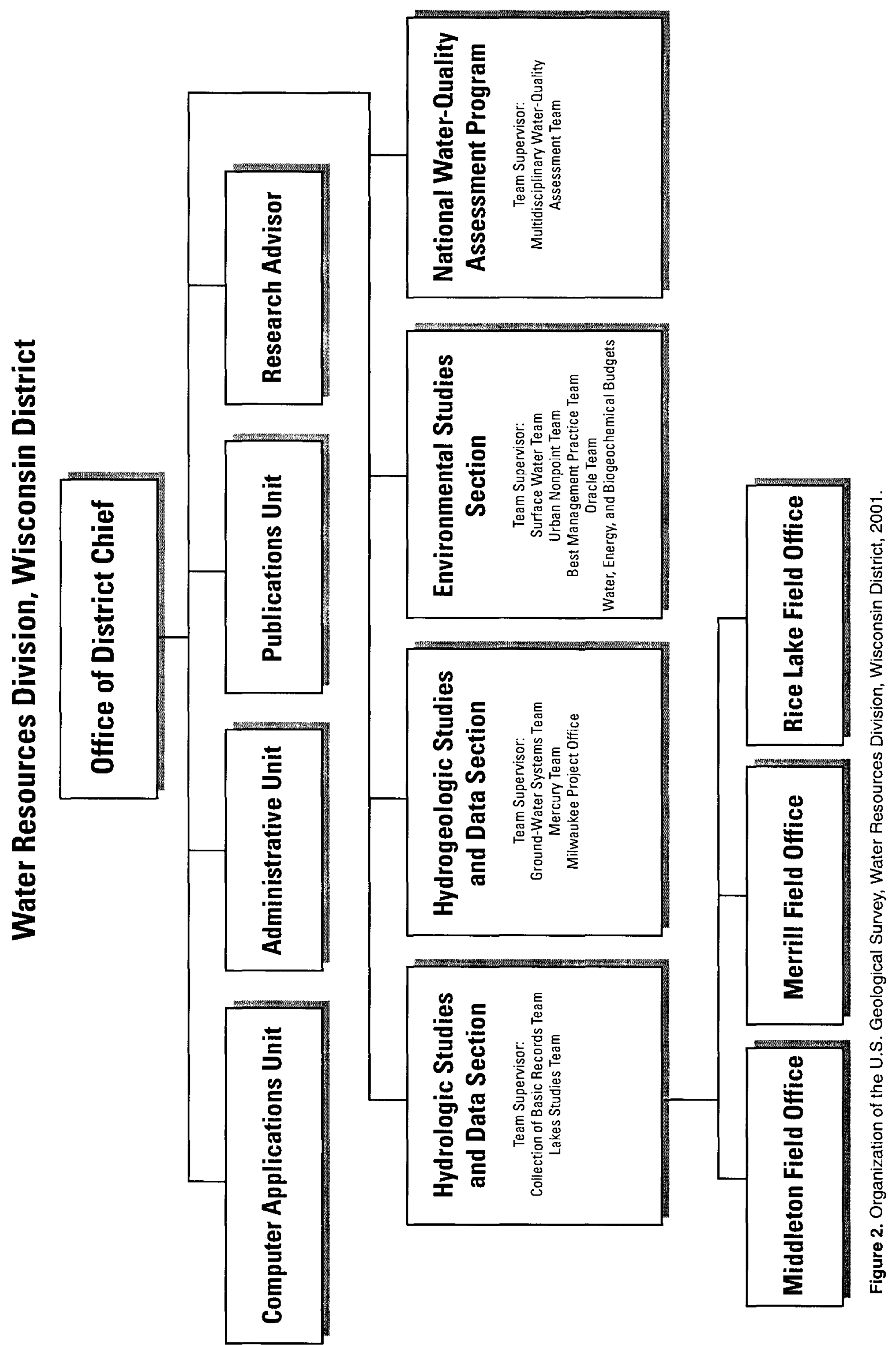




\section{Responsibilities}

Surface-water data-collection personnel within the District are located in three field offices and the District Office in Middleton. The primary responsibility for ensuring that surface-water programs in the District are adequately planned rests with the District's senior staff, including the District Chief; the Chief of the HSDS; and the District Surface-Water Collection of Basic Records (SW CBR) Project Chief; and the Surface-Water Specialist. Members contribute their specialized knowledge to the formulation of policies and plans for short- and long-term programs and to the establishment of criteria for determining the type and scope of surface-water activities to undertake.

The responsibility for the preparation of, implementation of, and adherence to the QA policies described in the QA Plan lies with the District Chief (Schroder and Shampine, 1992, p. 7). The District Chief has delegated preparation of the QA Plan to the HSDS Chief, who is responsible for any future updates and revisions.

All individuals involved in surface-water activities are responsible for implementing quality assurance. Field Office supervisors and project chiefs assume much of the responsibility; however, the Section Chief and District Chief $r$ ave the final responsibility. Field Office Chiefs are 'sponsible for daily operations in their area; they as ign work according to an employee's knowledge and experience and are responsible for ensuring quality control, QA, and safety of employees, whether in the field or in the office.

The following is a list of responsibilities of District personnel involved in the collection, processing, storage, analysis, or publication of surface-water data.

The District Chief is responsible for:

1. Managing and directing District programs, including all surface-water activities, and delegating surface-water activities, where applicable, to the HSDS Chief and ESS Chief.

2. Ensuring that surface-water activities in the District meet the needs of the Federal Govermment, the Wisconsin District, State and local agencies, other cooperating agencies, and the public.
3. Ensuring that all aspects of this QA Plan are understood and followed by District personnel. This responsibility is fulfilled by the District Chief's direct involvement or through clearly stated delegation to other personnel in the District.

4. Resolving any conflicts or disputes related to surface-water activities within the District.

5. Ensuring that employees are properly trained and informed about procedural and technical communications from Region and National headquarters.

6. Ensuring on-the-job safety and health of all District personnel.

7. Ensuring that all publications and other technical communications released by the District are accurate and comply with policies of the USGS.

The Chief of the HSDS, along with the Chief of the SW CBR (00100) project, is responsible for:

1. Reviewing, evaluating, and advising surface-water personnel on the technical adequacy of the methods of collection, analysis, and interpretation of hydrologic data intended for technical reports.

2. Serving as co-advisor, with the SurfaceWater Specialist, to the District Chief and project chiefs on the collection, processing, and publication of hydrologic data.

3. Participating with the District Chief and other staff members in planning and developing hydrologic-data programs and interpretive studies, in cooperation with other Federal and State agencies.

4. Serving as a District contact for cooperating agencies and responding to information inquiries from cooperating agencies and the public.

5. Ensuring on-the-job safety and health of all supervised employees.

6. Managing the data-collection program, which includes processing and publication of data by the District and three field offices, and serving as the principal contact between cooperators and the USGS. 
7. Ensuring that surface-water data-collection, -processing, and -analysis activities associated with the Wisconsin surface-water network conform to the procedures, goals and policies of the WRD, the Office of Surface Water (OSW), the Office of Water Quality (OWQ), and the District.

8. Developing annual work plans, and preparing and managing the budget to operate the data-collection program in an efficient and fiscally responsible manner.

9. Ensuring that records for all surface-water data stations are correctly computed, checked, and appropriately reviewed and that identified deficiencies are corrected.

10. Serving jointly with the Surface-Water Specialist as the District Flood Coordinators. Coordinating site visits of USGS personnel during floods or other unusual or high-water events, and compiling the collected data; apprising District, Regional, and WRD Headquarters staff of current events using electronic media; sending press releases to local and national news media to disseminate data and to inform the public of real-time streamflow conditions; and coordinating among the USGS, the National Weather Service (NWS), the U.S. Army Corps of Engineers, and other Federal and State agencies.

11. Ensuring that supervised personnel receive appropriate training for safe and proper collection and computation of surface-water records.

12. Ensuring that supervised personnel conduct work in accordance with safety policies established by the USGS and the District.

13. Preparing and updating the District Flood Plan.

14. Overseeing the production and publication of the Wisconsin annual water-data report.

15. Coordinating with the database manager to ensure that the surface-water databases are properly maintained and updated.

16. Overseeing the maintenance of the official drainage-area map files for the District.

17. Issuing station-identification numbers for new surface-water stations in the District.

18. Participating in outreach programs to promote the visibility of the USGS.
The Surface-Water Specialist and Chief of the Flood-Frequency Project is responsible for:

1. Participating with the District Chief and other staff members in planning and developing hydrologic-data programs and interpretive studies, in cooperation with other Federal and State agencies.

2. Managing and conducting investigations in selected aspects of the surface-water discipline, including complex hydrologic and hydraulic analyses, statistical methods and hydraulic-engineering principles.

3. Managing the flood-frequency project, approving indirect streamflow measurements, and approving the crest-stage gage computations and records.

4. Managing the peak-flow and basincharacteristics databases.

5. Ensuring that correct technical procedures are used in the collection, computation, analysis, and interpretation of surface-water data.

6. Providing technical assistance for analysis and interpretation of surface-water data collected during hydrologic investigations.

7. Ensuring that correct procedures are followed for and checking all indirect measurements of streamflow.

8. Serving jointly as the District Flood Coordinator with the SW CBR Project Chief.

9. Assisting in training personnel involved in surface-water data collection, computation, and analysis.

10. Serving as technical advisor for surfacewater activities to the senior staff and other District personnel.

The Field Office Chiefs and hydrologic technicians are responsible for:

1. Developing stage-discharge ratings at gaging stations by measuring stream discharge at various stages; computing discharge records for streamflow-gaging stations using the stage-discharge relation and stage record; reviewing the development of stage-discharge curves relative to channel condition and measurement trends to determine appropriate shifts; reviewing and 
checking accumulated data to determine the accuracy of results obtained at streamflowgaging stations; recommending improvements in techniques and methods; writing station analyses that describe the annual streamflow characteristics and the procedures used to compute discharge records; and preparing data in final publication format.

2. Installing, servicing, and maintaining all types of stream-gaging structures, equipment, and recording instruments in their area.

3. Preparing sections of reports for use by the USGS, other Federal and State agencies, and the public.

4. Representing the District when conducting surface-water-related business with cooperating agencies and the public in their area.

5. Ensuring on-the-job safety and health of all supervised employees.

6. Preparing plans for new streamflow-gaging stations, artificial controls, cableways, and other equipment associated with streamflowgaging structures and for the rehabilitation of existing stations; making reconnaissance and surveys for the location of new streamflowgaging stations; preparing orders for materials and cost estimates of major construction and repair jobs; and procuring materials. Constructing and maintaining structures and rebuilding installations that have been destroyed or damaged.

7. Running level circuits to establish or to check gage reference datums or peak stages from high-water marks.

The Database Administrator is responsible for:

1. Maintaining the District's electronic and archived files of streamflow and water-level records; submitting reviewed surface-water data to WRD Headquarters for inclusion in the National database; working with Field Office Chiefs and other District personnel in the acquisition and compilation of surfacewater data.
2. Assisting others in the District to coordinate the real-time surface-water data program, including determining data requirements for existing and new real-time surface-water stations, reviewing and verifying incoming real-time data, and monitoring real-time data for inclusion on the District's World Wide Web (WWW) home page.

3. Assisting the Computer Specialist as the Automated Data Processing System (ADAPS) database administrator.

The Cableway Specialist is responsible for:

1. Serving as technical advisor concerning cableway designs and construction techniques to the senior staff and other District personnel.

2. Advising personnel about requirements for inspections and documenting of construction history and maintenance.

3. Reviewing and approving cableway designs.

The Computer Specialist is responsible for:

1. Ensuring that data integrity is preserved by performing regular backup of data files; ensuring that archived data, such as historical unit-values, are protected; providing assistance in restoring archived values as necessary; and installing USGS software, such as the National Water Information System (NWIS), in a timely fashion.

2. Assisting users in connecting various hardware components to the District computer system.

The District Safety Officer:

1. Consults with the District Chief and supervisory staff to ensure that USGS and WRD safety programs are operational in the District.

2. Identifies job safety and health hazards, instructs employees on job-safety requirements, reviews accident reports, initiates corrective measures for violations of Occupational Safety and Health Act standards, and directs periodic inspection of all work places, including streamflowgaging stations. 
3. Consults with supervisors to determine safety needs for all employees, prepares District safety plans, and informs supervisors of safety training and equipment needed to safely complete job assignments.

Other District individuals who assist in surfacewater-related activities may include the following.

All Project Chiefs are responsible for:

1. Ensuring that surface-water data collected, computed, analyzed, or interpreted as a part of their project conform to the policies and procedures outlined in this plan.

2. Ensuring that collection, computation, analysis, and interpretation of surface-water data as a part of their projects are done in accordance with all applicable QA guidelines.

Personnel from other sections are available to provide assistance during periods of peak streamflow or other hydrologic events. When the need arises, personnel from the HSDS will contact the Chief, ESS, to request assistance. The assisting personnel generally will accompany Field Office personnel to ensure timely and safe data collection. These field assignments can vary from 1 day to more than 1 week.

\section{COLLECTION OF STAGE AND STREAMFLOW DATA}

Many of society's daily activities, including industry, agriculture, energy production, waste disposal, and recreation, are closely linked to streamflow and water availability; therefore, reliable surface-water data are necessary for resource management and planning. The collection of stage and streamflow data is a primary component in the ongoing operation of streamflow-gaging stations (referred to in the remainder of this report as gaging stations) and other water-resource studies conducted by the Wisconsin District.

The objective of operating a gaging station is to obtain a continuous record of stage and discharge at the site (Carter and Davidian, 1968, p. 1). A continuous record of stage is obtained by installing instruments that sense and record. The water-surface elevation in the stream. Discharge measurements are made at periodic intervals to define or verify the stage-discharge relation and to define the time and magnitude of variations in that relation.

\section{Installation and Maintenance of Gaging Stations}

Proper installation and maintenance of gaging stations are critical activities for ensuring quality in streamflow-data collection and analysis. Effective site selection, correct design and construction, and regular maintenance of a gage can make the difference between efficient and accurate determination of drainage-basin discharge and time-consuming, poor estimations of flow.

Sites for installation of gaging stations are selected with the intent to meet the purpose of each specific gage. Additionally, sites are selected with the intent of achieving, to the greatest extent possible, ideal hydraulic conditions. Criteria that describe the ideal gagingstation site are listed in Rantz and others (1982, p. 5). These criteria include unchanging natural controls that promote a stable stage-discharge relation, a satisfactory reach for measuring discharge throughout the range of stage, and the means for efficient access to the gage and measuring location. Other aspects of controls considered by District personnel when planning gage-house installations include those discussed in Kennedy (1984, p. 2).

Field Office Chiefs and SW project chiefs are responsible for selecting sites for new gaging stations with input from cooperating agency officials, the Surface-Water Specialist, and the Chief, HSDS, when needed. The process of site selection includes discussion with personnel of the cooperating agency to determine the purpose(s) of the gaging station, as well as operation and data needs. Preliminary site selection starts with reviewing topographic and county maps and determining the type of gaging equipment needed to collect the data. Computer and paper files are searched to determine whether previous records have been collected at or near the selected site. USGS personnel, sometimes accompanied by cooperating agency officials, visit the stream reach to determine the best location for the gage. After a potential site has been selected, the following information is recorded: land ownership and whether permission is needed to install the gage, access to the proposed gage, gage location, needed equipment, availability of electricity and phone lines, high-and low-water measuring and control conditions, 
estimate of stage of the 100-year flood, and any suspected anomalies that might affect the stability of the stage-discharge relation. The Field Office Chief is responsible for proper documentation of agreements with property owners and Federal or State permits if needed. The project chief is responsible for approving the site selection and design. The Field Office Chief is responsible for constructing the gage, installation of recording instruments, establishing the gage datum, and inspecting and approving the completed installation.

Personnel assigned to operate gaging stations must ensure that equipment, gage houses, and cableways are kept in good repair. A program of careful inspection and maintenance of equipment and gage houses promotes the safe collection of reliable and accurate data. Failure to maintain equipment and structures can result in unreliable data, missing record, and unsafe working conditions. To ensure proper maintenance, personnel assigned to the station should inspect each assigned station annually. Improvements needed or deficiencies observed at the gaging station and any unsafe conditions are documented annually on the gaging-station and cableway safety-inspection checklist. District policy requires that a visual inspection be performed at sites by field personnel during each visit. To prevent the buildup of sediment or the clogging of intakes, stilling wells are cleaned and intakes are flushed during field visits following major events, or as needed. Other maintenance activities performed on a regular basis include installation of heat lamps and subfloors each winter to reduce the effects of cold temperatures, checking and replacing batteries and nitrogen cylinders, cleaning the gage house, painting, and cutting brush near the gage house and cableway.

The Field Office Chief has the responsibility to ensure that gages and gage houses are kept in good repair. To ensure these responsibilities are carried out, the project chief or Field Office Chief receives reports from field personnel, inspects sites when necessary, and takes corrective action, or requests appropriate funding if needed. Deficiencies are communicated orally to the field personnel who service the gages, who are responsible for ensuring that they are remedied.

\section{Measurement of Stage}

Many types of instruments are available for measuring the water level, or stage, at gaging stations. Gages can be either nonrecording (Rantz and others,
1982 , p. 24) or recording (Rantz and others, 1982, p. 32). Because the uses to which stage data may be put cannot be predicted, OSW policy specifies that surfacewater stage records at stream sites be collected with instruments and procedures that provide sufficient accuracy to support computation of discharge from a stage-discharge relation, unless greater accuracy is required (OSW Memorandum 93.07; see appendix 1).

In general, operation of gaging stations for the purpose of determining daily discharge includes the goal of collecting stage data at the accuracy of + or $-0.01 \mathrm{ft}$ (foot) or 0.2 percent of the effective stage being measured (OSW Memorandum 93.07). An explanation of WRD policy on stage-measurement accuracy as it relates to instrumentation is provided in OSW Memorandum 93.07. OSW Memorandum 96.05 (see appendix 1) reaffirms and clarifies this policy.

The types of instruments installed at any specific gage house operated by the Wisconsin District depend on the needs of the cooperator, the availability of utility lines, hydraulic conditions, telemetry, the expected range of stage, the types of data to be collected, and the expected life of the gage. Types of water-level sensors generally used by personnel in this District include float-type sensor/potentiometers, pressure sensors, and CSGs; types of recorders used are Campbell CRIOX and CR500 dataloggers with phone modems for remote data retrieval.

The Project Chief, after consulting with the Chief, HSDS, if needed, is responsible for selecting the type of stage recorder needed at each gaging station. The Field Office Chief ensures that any new equipment has been installed safely and correctly. If non-routine equipment such as an acoustical velocity meter (AVM) is to be installed, field personnel may need to obtain instruction or assistance from District experts to ensure proper installation or maintenance of equipment. Proper maintenance of gage instrumentation or replacement, if needed, is the responsibility of field personnel servicing the gage.

Accurate stage measurement requires not only accurate instrumentation but also proper installation and continual monitoring of all system components to ensure their accuracy does not deteriorate with time (OSW Memorandum 93.07). To ensure that instruments located within the gage house record water levels that accurately represent the water levels of the body of water being investigated, "inside" and "outside" waterlevel readings are obtained by independent means. For example, at a stilling-well gaging station, all recording 
instruments are calibrated to an inside staff or electrictape gage located on the recorder shelf, and outside readings are made from a staff or reference point, or with a wire-weight gage mounted on a bridge rail near the gage house. The inside gage readings may not always equal outside readings, especially if the gages are not in the same pool at all ranges of stage. At stations equipped with a stilling well, the base or reference gage typically is an instrument installed inside the gage house, and other gages are installed outside the gage house to indicate whether or not the instruments are operating properly (Rantz and others, 1982, p. 53 and p. 64).

Personnel servicing the gaging station are responsible for comparing inside and outside readings during each site visit to determine whether the outside water level is being represented correctly by the recording equipment. If a deficiency is identified, the employee servicing the gage is responsible for thoroughly documenting the problem in the field notes and either correcting the problem immediately or contacting the Field Office Chief so that corrective actions can be taken at the earliest opportunity. The primary recorder or recorders should be adjusted to agree with the base gage if the readings differ by $0.02 \mathrm{ft}$ or more.

The person assigned to the gaging station is responsible for ensuring that instruments installed at gaging stations are properly serviced and calibrated by carefully reviewing all field data, examining plots of the raw data, comparing hydrographs with those from other stations, and using available information on weather and site conditions. Field personnel should be familiar with and understand manufacturer product manuals and use and care instructions, and applicable TWRI's and WRD memorandums. Ideally, all sensors and recorders should be bench tested prior to installation at the gage. This practice will ensure proper calibration of equipment and may eliminate additional site visits. When instruments are installed at the gage, they should be checked for loose fittings and connections, and improper alignment or orientation. Sensors and recorders should be calibrated against reference gages and manually operated to test their performance. When deficiencies are identified, the field person should correct the problem immediately or replace the faulty equipment. Each field vehicle should be supplied with adequate tools and spare parts to repair or replace equipment. If a separate trip is needed to correct the problem at the gage, it should be done as soon as is reasonably possible. Individuals who have questions related to the calibration and maintenance of water-level recorders should contact their Field Office Chief or, in his or her absence, the project chief or other District expert.

\section{Gaging-Station Documents}

District policy specifies that certain documents be placed in each gage house for the purpose of keeping an on-site record of observations, equipment maintenance, structural maintenance, and other information helpful to field personnel. Documents maintained at each gage house include (1) the most recent tabular listing of the stage-discharge relation (rating table); (2) a graph of the stage-discharge relation (rating curve) on which measurements are plotted; (3) a log, updated by field personnel during each site visit, describing control conditions and listing gage readings, discharge measured, gaging-station maintenance performed, and instrument maintenance performed; (4) the most recent station description listing all gages and reference marks at the site, locations of measurement cross sections with guidance on which to use at various stages, information related to extreme events including the potential for channel storage between the gage and measuring section during flood conditions, and other information (see the section "Site Documentation, Station Descriptions" in this report); (5) a traffic control plan for bridges, where appropriate; (6) a calendar; and (7) important contacts and telephone numbers.

The field person assigned to the gaging station is responsible for updating gage documents in the gage house as needed. Nonassigned field personnel who visit a gage house and identify a need to update one or more of the documents should notify the Field Office Chief. Employees who have questions about documents or information should be kept in a gage house, when the documents should be updated, or appropriate methods of appending logs or plotting measurements should contact the Field Office Chief.

\section{Levels}

The various gages at a gaging station are set to register the elevation of a water surface above a selected level reference surface called the gage datum. The gage's supporting structures-stilling wells, backings, shelters, bridges, and other structures-tend to settle or rise as a result of earth movement, static or dynamic 
loads, vibration, or battering by floodwaters and floodborne ice or debris. Vertical movement of a structure makes the attached gages read too high or too low and, if the errors go undetected, may lead to inaccuracies in streamflow records. Leveling, a procedure by which surveying instruments are used to determine the difference in altitude between points, is used to set the gages and to check them for vertical movement from time to time (Kennedy, 1990, p. 1). Levels are run periodically to all benchmarks, reference marks (RMs), reference points, and gages at each station to determine if any datum changes have occurred (Rantz and others, 1982, p. 545).

District policy requires that levels be run at newly established gaging stations at the time of construction and installation and then annually until three sets of levels have been obtained. If the history of levels shows the gage to be stable, then levels are run to established gaging stations at intervals ranging from 3 to a maximum of 5 years. If the gage has been found to be unstable, levels will be run yearly or more frequently, as needed. Levels for established CSGs should be run annually or, if the gage is found to be stable, at 2-year intervals. Additional leveling surveys should be run as needed when conditions such as known instability, nearby construction, unexplained differences in readings or vandalism or other damage exist; before discontinuing, relocating, or resetting a gage; or when any other condition or circumstance casts doubt on the reliability of the gage settings or datum. Gages should be reset to agree with levels when the levels indicate a vertical change greater than $0.015 \mathrm{ft}$. When gages are reset, field personnel should document the reset by writing the "found" and "left" gage readings and the time associated with each reading on the level note sheet. Levels are run to all gages and both the inside and outside water surfaces are determined by direct levels, or by taping down from a reference point if direct levels are not practical. When levels are run, each gage or established mark should be read twice, with readings separated by at least one move of level instrument. The level loop must close within $0.005 \mathrm{ft}$ from the starting elevation; or if this error is exceeded, the set of levels shall be run again.

Leveling procedures followed by District personnel pertaining to circuit closure, instrument reset, and repeated use of turning points are described in Kennedy (1990) and in OSW Memorandum 93.12. When practical, at least three RMs are established for all gaging stations. At least one of the RMs is to be located away from bridges, cableways, and the gage-house foundation. The level instruments are kept properly adjusted and checked by use of a peg test as described in Kennedy (1990, p. 13). Peg tests are done periodically on each instrument, typically once each field season prior to running levels. If the accuracy of an individual instrument becomes suspect for any reason, however, a peg test is performed immediately. Results of the tests are recorded on a log and kept in a levels file in each office. If an instrument is found to be in error, level runs made with the erroneous instrument are examined and actions are taken to correct any errors, or the level runs are determined to be invalid and the level procedures are repeated.

If a gaging station is established near an existing benchmark, or if a benchmark is placed near the station after it has been established, the elevation of the gage datum with respect to sea level, or sea-level elevation for "zero" of the gage should be determined. This is done by running levels to determine sea-level elevations of pertinent gage features and the water surface at the gage. The sea-level elevation of the gage is assigned a stage of $0.00 \mathrm{ft}$, with all stage measurements thus representing elevation, in feet, above this datum. Any stage reading can then be converted back to elevation above sea level by adding the measured stage to the sea-level elevation of the gage datum. The elevation of the benchmark is the elevation as determined from the latest level-net adjustment. The date of that adjustment should be obtained from the agency that established it. Benchmarks should be accepted only when their reliability and basis of establishment have been authenticated. Published references to a benchmark used by the USGS in referring river stages to sea level should always include the name of the agency responsible for the benchmark and the date of the level-net adjustment used in determining its elevation.

When a gaging station is established, a "reference" or "base" gage will be designated. All gage heights typically will be referred to this gage. The reference gate should be a gage that can be checked by levels and for which datum corrections can be determined and made easily. Reference gages for different types of stations are usually as follows: 
-Recording station with stilling well - inside gage. -Recording station with transducer - outside gage.

-Wire-weight gage - check bar and the dial are set, by levels, to the water surface at a low stage.

-Staff gage station - lowest gage.

-Crest-stage gage - top of lower cap.

If the designated "reference" or "base" gage is out of operation and another gage is used temporarily, readings from the latter should be converted to equivalent readings for the reference gage. The procedure for this conversion is to apply a datum correction (if applicable) by comparative readings, from levels, or a combination of the two.

A sheet summarizing results of all level runs at gaging stations is maintained as part of the information for each station. Results of level runs should be added to the District summary sheet after completion. The sheet enables a quick review of all level results and assists in identifying unstable reference gages, RMs, reference points, gage supports, and errors in outside staff gages and wire-weight gages. The level-summary sheet also enables a quick comparison of gage settings, errors found, and corrections applied throughout the period of data collection.

It is the responsibility of each Field Office Chief to ensure that levels are run with the appropriate frequency, that levels are run correctly and level notes are completed correctly, and that all field level notes are checked. The level information is entered on the levelsummary sheet by the individual who computes the annual discharge record. The level-summary sheet is stored in the station computation folder and should be reviewed annually.

\section{Site Documentation}

Thorough documentation of qualitative and quantitative information describing each gaging station is required. The station description and photographs provide a permanent record of site characteristics, structures, equipment, instrumentation, elevations, location, and changes in conditions at each site. Information per- taining to where this documentation is maintained is discussed in the section of this report entitled "Office Setting."

\section{Station Descriptions}

A station description is prepared for each gaging station and it becomes part of the permanent record for each station. A District Site File Entry Form with required information should be completed for new stations soon after the station location is determined and given to the SW CBR Project Chief, who assigns the downstream-order station number and name, and passes the form to the database administrator for establishment of NWIS computer header information and data descriptors. District policy requires that the station description be written by the time that the first year of record is computed. The Field Office Chief is responsible for ensuring that station descriptions are prepared correctly in a timely manner and are updated. Station descriptions are reviewed annually and updated as needed by the person computing the annual record.

Station descriptions are written to include specific types of information in a consistent format (Kennedy, 1983 , p. 2). An example station description follows. When the original station description for a gaging station is being written, a standard form can be obtained from the Hydrologic Assistant in the HSDS. The latitude-longitude coordinates and quarter-quarter-section location are determined from a USGS 7.5-minute topographic map. The gage location is plotted on the set of topographic maps maintained as the master Drainage Area Maps. Each gaging station is assigned a downstream-order number. One person in the District, the $S W$ CBR Project Chief in the HSDS, is responsible for assigning these numbers for all USGS sites in Wisconsin. All current station descriptions are stored in a central computer subdirectory (STATION.DESCRIPTION) in the home directory of the Hydrologic Assistant, accessible by all USGS personnel. Paper copies of the description are located in the station file in each field office and in field files kept by the field person. 


\section{EXAMPLE STATION DESCRIPTION}

05362000 Jump River at Sheldon, WI

Location.-Lat $45^{\circ} 18^{\prime} 29^{\prime \prime}$, long 90 57'23", in SE 1/4 SW 1/4 sec.26, T.33 N., R.5 W., Rusk County, on right bank 10 ft downstream from Highway $\mathrm{C}$ bridge in Sheldon, $1,500 \mathrm{ft}$ upstream from Shoulder Creek, and $11 \mathrm{mi}$ upstream from mouth.

Established.-July 22, 1915, by H.C. Beckman, USGS. Water-stage recorder Feb. 9, 1919, to Aug. 31, 1941 (gage destroyed by flood); various other gages at same general location for other periods. Sept. 28,1964 , bubble gage installed by K.S. Brigham and S.J. Field, USGS. Sutron Accubar pressure sensor installed July 29, 1998.

Drainage area. $-576 \mathrm{sq} \mathrm{mi}$.

Gage.-A CR-10 datalogger with phone modem receives input from a Sutron Accubar pressure sensor. Unit values recorded each 15 min; data retrieval automatically each day. Shelter is a $5 \mathrm{ft} \times 5 \mathrm{ft}$ walk-in metal building. A NWS precip gage is mounted on the roof and is integrated to the CR-10. The orifice enters the river at the right bank, about $10 \mathrm{ft}$ downstream from the gage. Primary outside reference is a filed arrow on the downstream side of the bridge. The crest gage is located on a 24 -inch oak, about $115 \mathrm{ft}$ southwest of the left down stream corner of the bridge.

Pertinent Elevations (gage datum)

Instrument shelf $-31.6 \mathrm{ft}$

Floor - about $28 \mathrm{ft}$

Ground level at house - about $26.5 \mathrm{ft}$

Orifice level - $1.92 \mathrm{ft}$ by tape-up to W.S. at date of installation

Datum of gage.-1,092.75 ft above National Geodetic Vertical Datum of 1929.

History.-Established 7/22/15. USGS water-stage recorder operated 2/9/19 to 8/31/41 (destroyed by flood). Tape gage in creamery well house $400 \mathrm{ft}$ upstream at same datum used $4 / 2 / 53$ to $2 / 18 / 54$. Various gages near same location used during other periods. A manometer bubble gage was installed in a $5 \mathrm{ft} \times 5 \mathrm{ft}$ concrete gage house (located $5 \mathrm{ft}$ downstream from Hwy. C bridge at right bank) on 9/28/64, with strip-chart recorder used to 5/5/71 and ADR from 5/5/71 to 12/22/94. (A DCP was in place from May 1984 to Dec. 18 , 1990.) A CR-10 replaced the ADR 12/22/94, and was used with existing manometer until 7/29/98. (Strip-chart recorder used as backup for entire period.) A new Hwy. C bridge was built in 1998. Old gage and equipment was removed for construction. New gage built $20 \mathrm{ft}$ north and $15 \mathrm{ft}$ west of old concrete building. New orifice about $12 \mathrm{ft}$ downstream from old orifice. The new gage with Sutron pressure sensor and CR-10 began operation $7 / 29 / 98$. 
References and benchmarks:

$\underline{\mathrm{RM} 12}$, a transition reference (used to transfer datum during 1998 bridge construction), is no longer needed as part of the regular level circuit, but could be used in case of a total loss of other references. RM 12 is the top of the water hydrant, $69 \mathrm{ft}$ north of gage; established $5 / 16 / 96$ at elevation $37.952 \mathrm{ft}$.

$\underline{\mathrm{RM} 13}$, a 1/2-inch hex-headed lag at streamward base of 14-inch cedar, $20 \mathrm{ft}$ streamward of gage; established 8/26/98 at 27.048 ft. $\underline{\mathrm{RM} 14}$, a DOT tablet on top of right downstream wingwall, set $11 / 98$ by DOT; USGS established elevation $12 / 14 / 98$ at $28.795 \mathrm{ft}$. RP 2, a 1-inch rebar at right bank, slightly downstream from gage and $1.5 \mathrm{ft}$ upstream from orifice; established 7/24/98 at $3.912 \mathrm{ft}$. RP 4, a filed arrow on left downstream side of twelfth guardrail post from right downstream end of bridge; established 12/14/98 at $30.688 \mathrm{ft}$.

C.G. bracket, top of lower bracket for crest gage, located on 24-inch oak, about $115 \mathrm{ft}$ SW of left downstream corner of bridge; established at $12.192 \mathrm{ft}$.

Channel and control.-A coarse gravel rapids $1,000 \mathrm{ft}$ below is the control and is subject to slight shifts. Channel has fairly clean gravel bottom. The right bank is high. The left bank overflows at extremely high water. Channel fairly straight above gage but curves to left onethird mile below the gage.

Discharge measurements.-Low and medium stage measurements are made by wading $600 \mathrm{ft}$ below gage; another site is $300 \mathrm{ft}$ above 1 railroad bridge upstream from gage and is best for stages below $3.5 \mathrm{ft}$. Wade below $4.5 \mathrm{ft}$ gage height. Medium and high stage measurements made from the bridge at the gage. The bridge is marked at 5 - $\mathrm{ft}$ intervals on downstrean side. (Initial point is right abutment.) Measurements under ice cover are usually made about $600 \mathrm{ft}$ below gage, at same site as wading measurement. Floods. - $-46,000 \mathrm{cfs}$ Aug. 31, 1941, $18.8 \mathrm{ft}$ gage height, from flood marks. (This flood destroyed former gage.)

Winter flow.-Complete ice cover in winter.

Point of zero flow.-Shifting. About $3.5 \mathrm{ft}$ in 1959; about $2.7 \mathrm{ft}$, gage datum, on July 23, 1964; about $2.0 \mathrm{ft}$, July $30,1998$.

Regulation and diversion.-No known regulation.

Accuracy.-Conditions suitable for good records.

Observer data. -None.

Cooperation.-Wisconsin Department of Natural Resources contributes half the annual operation and maintenance cost.

Sketch and Photographs.-Colored slides and black and white photos are in the photograph file.

Revised March 16, 1999

By T.J. Popowski 


\section{Photographs}

Field personnel photograph newly installed gage houses, station controls, reference marks, cableways, and upstream and downstream views of the channel to document gaging-station construction, changes in control and channel conditions (including geometry and vegetation), damaged structures, unusual hydrologic events such as extensive backwater or high-water flow conditions, or to supplement written descriptions. All field personnel are encouraged to carry an inexpensive camera for recording these conditions and events. If a camera is not available, field personnel may purchase an inexpensive disposable camera as needed. The back of each photograph that becomes part of the station record is identified by writing with a permanent-ink marker the station number and name, date, gage height and discharge (if known), and a brief description of what the photograph shows. Slides also should be labeled with the date and station name and number. The videotaping with narration of activities and significant events also is encouraged. The District video camera may be checked out by request. Videotapes can be purchased through regular procurement procedures. The same information that is included on photographs should be written on the videotape label. Photographs for the current year are placed in the current station folder. Older photographs are maintained in the station history folder.

\section{Direct Discharge Measurements}

Direct measurements of discharge are made with any one of a number of methods approved by WRD. The most common is the current-meter method, which is the summation of the products of the subsection areas of the stream cross section and their respective average velocities (Rantz and others, 1982, p. 80). Procedures used for current-meter measurements are described in Rantz and others (1982, p. 139); Carter and Davidian (1968, p. 7); and Buchanan and Somers (1969, p. 1).

When personnel measure stream discharge, attempts are made to minimize errors. Sources of errors are identified in Sauer and Meyer (1992). Errors can be random, such as depth errors associated with soft, uneven, or mobile streambeds; uncertainties in mean velocity associated with vertical-velocity distribution errors; and pulsation errors. Errors also include systematic errors, or bias, associated with improperly cali- brated equipment or the improper use of such equipment. To minimize systematic errors, each field trip is performed at least annually by someone other than the person who usually is assigned the group of stations, and a different set of equipment is used. Field trips also may be rotated to different field personnel every 2 to 3 years. Field areas are assigned by the Field Office Chief. At the gaging station, the field person ultimately is responsible for proper equipment maintenance and performance. The TWRI series (Smoot and Novak, 1968) and OSW Technical Memorandum No. 99.06 discuss the maintenance of vertical-axis type current meters. The accepted spin tests are those described in Smoot and Novak (1968). The results of the spin tests are recorded on the Current-Meter Log maintained for each meter as outlined in OSW Memorandums 89.07 and 99.06. When discharge in clear-water streams is measured, the meter should be inspected, cleaned and oiled once a day and then spin tested. When streams are turbid, the meter should be cleaned and oiled after each measurement. Employees who have questions concerning the appropriate procedures for making discharge measurements should contact their Field Office Chief, SW CBR Project Chief, or Chief, HSDS.

District policies related to the measurement of discharge by use of the current-meter method, in accordance with WRD policies, include the following procedures.

Depth criteria for meter selection.-District personnel select the type of current meter to be used for each discharge measurement on the basis of criteria provided by the OSW (OSW Memorandum 85.07), and Water-Supply Paper 2175 (Rantz and others, 1982). Occasions may arise during unusual hydrologic events that require deviations from the use of standard measuring methods. Meters are used with caution when a measurement must be made in conditions outside these criteria; any deviations from the criteria are noted and the measurement accuracy is downgraded accordingly. A change of meter is not recommended during a measurement when a few subsections in a single measurement cross section exceed the stated ranges of depth and velocity. If the flow in the affected area represents less than 10 percent of the total discharge, then the error associated with these few subsections will not affect the error of the measurement significantly. It is left to the discretion of the field personnel making the measurement to change meters in situations where overflow conditions create a secondary channel, which effectively creates a different measurement cross section. 
Number of measurement subsections. - The spacing of observation verticals in the measurement section can affect the accuracy of the measurement (Rantz and others, 1982, p. 179). Observations of depth and velocity are to be made at a minimum of about 25 to 30 verticals, which are necessary so that no more than 5 percent of the total flow is measured in any one vertical. Even under the worst conditions, the discharge computed for each vertical should not exceed 10 percent of the total discharge and ideally should not exceed more than 5 percent (Rantz and others, 1982, p. 140). Exceptions to this policy are allowed in circumstances where accuracy would be sacrificed if this number of verticals were maintained, such as rapidly changing stage (Rantz and others, 1982, p. 174). Fewer than the ideal number of verticals may be used in very narrow streams (about $12 \mathrm{ft}$ wide when an AA meter is used and about $5 \mathrm{ft}$ wide when a pygmy meter is used) to avoid making the vertical spacing narrower than the width of the meter. Measurement of discharge is essentially a sampling process, and the accuracy of sampling results typically decreases markedly when the number of samples is less than about 25.

Other direct methods of measuring discharge.WRD and OSW techniques and guidelines are to be followed when discharge is measured by other direct methods of measurement, such as the use of portable weirs, flumes, and volumetric methods. These portable devices are applied according to methods described in Rantz and others (1982, p. 263), Buchanan and Somers (1969, p. 57), and Kilpatrick and Schneider (1983). Acoustic Doppler Current Profilers (ADCPs) also are used in the District where conventional methods are not suitable. Standard methods for ADCP use in the District are documented and presented in appropriate sections of this Plan.

Computation of mean gage height.-Mean gage height at the time of the discharge measurement and the instantaneous discharge measured are used to develop the stage-discharge relation (rating) at a gaging station. Procedures for the computation of mean gage height during a discharge measurement are to be used as presented in Rantz and others (1982, p. 170).

Check measurements.-A second discharge measurement is made for the purpose of checking a first discharge measurement when the measurement differs from the rating by more than 5 percent and the result of the first discharge measurement is suspect. The result is considered suspect if the measurement difference from the rating cannot be explained by control conditions or other conditions of the measurement. When a check measurement is made, the potential for systematic errors is minimized by using different stationing for verticals than those used during the initial measurement, by selecting a new measurement section, by inspecting and spin testing meters, or by changing meters. If the check measurement is within 5 percent of the first discharge measurement, the two measurements are considered to be reliable evidence of a shift in the stage-discharge relation.

Corrections for storage.-Discharge measurements made at a considerable distance from the station during times of changing stage will not be equal because of channel storage between the measuring section and the gaging station. Corrections for storage applied to measured discharges made some significant distance from the gaging station during a change in stage are discussed in Rantz and others (1982, p. 177) and in OSW Memorandum 92.09.

\section{Field Notes}

Thorough documentation of field observations and data-collection activities performed by field personnel is a necessary component of surface-water data collection and analysis. All information is recorded as it is obtained and is never left to be documented from memory. To ensure that clear, thorough, and systematic notations are made during field observations, discharge measurements are recorded by field personnel on standard discharge-measurement notes (Form 9-275). These notes include the following information:

1. Location identified by station name and number, or by latitude/longitude for a miscellaneous site;

2. Date, party (last name and initials), type of meter suspension, meter number, and spin test;

3. Local time of measurement, in military local (24-hour) time;

4. Bank of stream used as the starting point;

5. Gage readings and corresponding times;

6. Streamflow, cross-section, and control conditions;

7. Weather conditions; and

8. Other information affecting the accuracy of the discharge measurement and the stagedischarge relation.

Original observations, once written on the note sheet, are not erased. Original data are corrected by 
drawing a line through the erroneous value and then writing the correct value. Changes from original data are initialled by the person making the change. Some examples of original data on a discharge-measurement note sheet include gage readings, vertical stationing, depth observations, meter revolutions, and time. Examples of information on a discharge-measurement note sheet that is computed from original data, but is not considered original data, include mean gage height, stream width, mean velocity, and total discharge listed on the front sheet. District policy specifies that all discharge measurements be calculated in their entirety before field personnel leave the site, unless exceptional circumstances of safety or other priorities warrant departure from this policy.

Notations associated with miscellaneous surfacewater data-collection activities are to be made on a standard miscellaneous note sheet (Miscellaneous Field Notes-Form 9-275-D, January 1988). All miscellaneous notes are required to include, at a minimum, initials and last name of field-party members, date, time associated with observations, purpose of the site visit, and a detailed description of the observations.

A review of field notes by a checker or the Field Office Chief is required after each field trip and annually as part of a surface-water records review. The computer discharge calculation program QCOMP (on file in the District Office) may be used to compute and check measurements. Only those measurements made during floods, made during ice cover, that define extreme low flow or large shifts from the rating, and that are used to develop the rating are required to be checked. Deficiencies found in the content, accuracy, clarity, or thoroughness of field notes are identified and communicated orally to field personnel. The deficiencies are remedied by the Field Office Chief, who provides specific instructions to individuals who fail to record notations that meet USGS and District standards.

\section{Acceptable Equipment}

Equipment used by the Wisconsin District to measure surface-water discharge has been found acceptable by the WRD through use and testing. An array of acceptable equipment for measuring discharge includes current meters, timers, wading rods, bridge cranes, tag lines, and others (Rantz and others, 1982, p. 82; Smoot and Novak, 1968). Although an official list of acceptable equipment is not available, Buchanan and Somers (1969), Carter and Davidian (1968), and Edwards and
Glysson (1988) discuss the equipment used by the USGS. The equipment in use has a long-term history of reliability and is available from the Hydrologic Instrumentation Facility (HIF) at Stennis Space Center, Mississippi.

The meters most commonly used by District personnel for measuring surface-water discharge are the Price AA current meter and the Price pygmy current meter. The technician or hydrologist using the current meter is responsible for its condition and maintenance. Methods followed by District personnel for inspecting, repairing, and cleaning these meters are described in Rantz and others (1982, p. 93), Buchanan and Somers (1969, p. 7), Smoot and Novak (1968, p. 9), and OSW Technical Memorandums 89.07 and 99.06.

Spin tests of current meters that meet minimum requirements (45 seconds for a Price pygmy meter and 2 minutes for an AA meter) are required prior to each field trip, and results are documented in a log that is maintained for each meter. Each field person maintains the $\log$ for the meters he or she uses. This log is part of the permanent archived record of the WRD (OSW Memorandum 89.07). Spin tests also are conducted if there is any indication that the performance of the meter has deteriorated. Repairs are made to the meters when deficiencies are identified through the spin test or inspection. Damaged current meters are not to be used under any circumstances; a spare meter carried as part of routine field supplies should be used instead.

In addition to performing the timed spin tests prior to field trips, field personnel are required to inspect the meter before and after each measurement to see that the meter is in good condition, that the cups spin freely, and that the cups do not stop abruptly. A timed spin test made before a measurement does not ensure that the meter will not become damaged or fouled during the measurement. If the meter's condition is suspect, a followup spin test after a field trip is encouraged. Field personnel must assess apparent changes in velocity or visually inspect the meter periodically during the measurement to ensure that the meter continues to remain in proper operating condition. Descriptive notations concerning the meter condition, such as "OK," or "free," or other such comments, are made at the appropriate location on the discharge measurement sheet. The Field Office Chief will inspect meters and equipment annually to ensure that field personnel maintain the equipment they use. If deficiencies are identified, it is the responsibility of the individual who uses the equipment 
in the field to correct the equipment problem immediately, by repair or replacement.

\section{Alternative Equipment}

New conditions and the development of new technology sometimes involve the collection of surfacewater data with alternative or advanced equipment. To demonstrate the quality of surface-water data collected with non-routine equipment, thorough documentation of procedures and observations must be maintained.

Equipment used by this District includes Acoustic Doppler Current Profilers (ADCPs) and Acoustic Velocity Metering (AVM) systems. In situations where standard equipment could be used and where standard parameter-relation ratings were available, the results obtained with these instruments were compared for consistency with those obtained with standard equipment. In situations where the standard equipment could not be used, success of the equipment was based on comparisons made at sites where standard equipment could be used.

The responsibility for ensuring that alternative equipment is utilized correctly and that documentation is comprehensive and is stored correctly is held by the individual using the equipment, the ADCP and AVM District expert checking the record, and, ultimately, by the Chief of the appropriate section. The ADCP specialist in the District has documented the methods for the proper use of the ADCP and the AVM and assures that manufacturer's specifications and procedures are adhered to. The methods are described in operating procedures and instructions on file in the District office. Policy and technical guidance on the use of ADCPs are provided in OSW Technical Memorandums 2002.01, 2002.02, and 2002.03.

\section{Indirect Discharge Measurements}

In many situations, especially during floods, it is impossible or impractical to measure peak discharges by means of a current meter. There may not be sufficient warning for personnel to travel to the site to make a direct measurement, or physical access to the site during the event may not be feasible or safe. A peak discharge determined by indirect methods is in many situations the best available means of defining the upper portions of the stage-discharge relation at a site. Because extrapolation of a stage-discharge relation, or rating, beyond twice the measured discharge at a gaging station is undesirable and may be unreliable, discharge measurements made by indirect methods during periods of high flow are important methods of data collection (Rantz and others, 1982, p. 334).

Data-collection and-computation procedures for indirect methods presented in Benson and Dalrymple (1967) are to be followed. That report includes policies and procedures related to site selection, field survey, identification of high-water marks, selection of roughness coefficients, computations, and the written summary. The District also follows procedures for measurement of peak discharge by indirect methods presented in Rantz and others (1982, p. 273).

In addition to the general procedures presented in Benson and Dalrymple (1967), the District follows guidelines presented in other reports that describe specific types of indirect measurements suited to specific types of flow conditions. The slope-area method is described in Barnes (1967) and Dalrymple and Benson (1967). The USGS uses the Manning equation when applying the slope-area method. Procedures for selecting the roughness coefficient are described in Arcement and Schneider (1989) and Coons (1995). The computer program SAC may be used to make computations of peak discharge with the slope-area method (Fulford, 1994). Procedures for the determination of peak discharge through culverts, based on a classification system that delineates six types of flow, are described in Bodhaine (1982). The computer program CAP, that assists in computations of peak discharge at culverts, is discussed in Fulford (1997). At situations where openchannel width contractions occur, such as flow under a bridge, peak discharge can be measured through use of methods described in Matthai (1967) and WSPRO, the water-surface profile computation model (Shearman, 1990) or HEC-RAS (Brunner, 2001).

Water-surface profiles along a stream channel are determined in association with selected discharges when studies are performed that involve delineation of flood plains or when extensions are made to stage-discharge relations at streamflow sites. District personnel are required to follow the procedures associated with step-backwater methods described in Davidian (1984). WSPRO may be used to assist in the computations of water-surface profiles with step-backwater methods (OSW Memorandum 87.05).

General guidelines that are followed by the District when making indirect measurements include those discussed in OSW Memorandum 92.10 and in Shearman 
(1990). Some general guidelines include obtaining a minimum of three cross sections, limiting conveyance ratios to between 0.7 and 1.4 , avoiding sections that result in flow moving in and out of critical flow, and other criteria. Violation of any one of the general guidelines and criteria does not necessarily invalidate an indjrect measurement (OSW Memorandum 92.10). The decision to accept or reject a measurement requires the hydrologic judgement of qualified individuals.

The District Surface-Water Specialist is responsible for ensuring that indirect measurements are performed correctly. The Surface-Water Specialist also reviews procedures and documentation for all indirect measurements made for rating extension and floodpeak determination. If deficiencies are found during the review, the Surface-Water Specialist informs the involved individuals and holds one-on-one training as needed. Measurements that are questionable and difficult to assess are reviewed by the Regional SurfaceWater Specialist or specialists outside the District, and the Surface-Water Specialist is responsible for ensuring that any revisions identified by the outside reviewers are corrected.

The Field Office Chief, Surface-Water Specialist, or SW CBR Project Chief determines when and where indirect measurements are made. In the Wisconsin District, indirect measurements generally are made, as a rule, at sites when peak flow is estimated to be at least twice the discharge of the greatest measured flow and sufficient head loss exists for the indicated type of indirect measurement, where it is impossible to obtain direct discharge measurements of high flow, and where direct measurements are unattainable because of hazardous high-water measuring conditions. The SW CBR Project Chief or Surface-Water Specialist should be consulted for assistance when a rating needs to be extended.

The person assigned the station is responsible for identifying when a peak has occurred and flagging high-water marks. Because the quality and clarity of high-water marks are best soon after an event, field personnel are required to have available in their field vehicles the necessary supplies for marking the stream reach, such as nails, survey flagging and stakes, and spray paint. Selection of a suitable reach of channel is extremely important in making an indirect measurement. At some streamflow-gaging stations and other sites, therefore, the stream reach for indirect measurements at specified ranges of stage has been preselected and that information has been included in the station description.

After each indirect measurement is computed, the graphs, field notes and data, plotted profiles, maps, calculations or computer output, and written analysis associated with the measurement are checked by the Surface-Water Specialist. The information is organized by grouping all information for a single measurement in a labeled folder that is filed in the appropriate station file.

The responsibility of maintaining the accuracy of the peak-flow data files, including computer database files, lies within the District (OSW Memorandum 92.10). It is the responsibility of Surface-Water Specialist to ensure that appropriate indirect-measurement results are entered into the peak-flow files and that the peak-flow files are correct. For further discussion on the update and review of the peak-flow files, refer to the section entitled "Database Management."

\section{Crest-Stage Gages}

Crest-stage gages (CSGs) are used throughout the WRD as tools for determining peak stages at otherwise ungaged sites, confirming peak stages at selected sites where recording gages are located, and determining peak stages along selected stream reaches or other locations, such as upstream and downstream from bridges and culverts. The OSW requires quality-assurance procedures comparable to those used at continuous-record stations for the operation of CSGs and for the computation of annual peaks at CSGs (OSW Memorandum 88.07).

Procedures followed by this District in the operation of CSGs are presented in Rantz and others (1982, p. $9,77,78)$. One or more gages are maintained at each selected site where measurement of peak water-surface elevations is required on a stream. Upstream and downstream gages are maintained at culverts or other structures where measurement of water-surface elevations is required to compute flow through the structure and to establish the resulting type of flow.

Except at sites where CSGs are used only to confirm or determine peak stages, stage-discharge relations are developed in association with the gage on the basis of direct or indirect high-water measurements. For new CSGs at locations where direct measurements are difficult to obtain, water-surface profile computations with the standard step-backwater method (Davidian, 1984; 
Shearman, 1990) may be used to develop a theoretical rating. Subsequent direct and indirect discharge measurements are made to verify the stage-discharge relation. Direct or indirect measurements are obtained annually or when significant events occur to verify or adjust the rating. Levels are run to the gage according to District policy or as soon as possible after significant changes in the gage occurred because of damage to the gage, reconstruction, or some other situation. When extremely high peaks occur, an outside high-water mark is found when possible to confirm the gage reading, and is described on the note sheet and flagged by a durable indicator (such as survey flagging tape) so that the elevation of the high-water mark can be determined the next time levels are run.

Field observations are written on CSG inspection note sheets. All field notes are required to include the station name and identification number, initials and last name of inspecting personnel, date, time of observation, gage height, measured discharge, and a sketched location of high-water marks if applicable. The Field Office Chief will ensure that correct data-collection procedures are used by personnel. This responsibility includes examining all note sheets of personnel in their first 3 years of experience, or when field personnel encounter unusual conditions. If a deficiency in datacollection activities is identified, the Field Office Chief will give the field person individual training. Policies and procedures for computation of peak discharges at CSGs and associated documentation are presented in the section entitled "Processing and Analysis of Stage and Streamflow Data."

\section{Artificial Controls}

Artificial controls, including broad-crested weirs, thin-plate weirs, and flumes, are built in stream channels to simplify the procedure of obtaining accurate records of discharge (Rantz and others, 1982, p. 12). Such structures serve to stabilize and constrict the channel at a section, reducing the variability of the stage-discharge relation.

Where artificial controls are installed as permanent structures, District policy is that stage-discharge relations be verified by making current-meter measurements throughout the range of stage, if possible, or by relying on the design rating when measurements cannot be made. Portable weir plates, flumes, and calibrated containers for volumetric measurements may be used by District personnel during low-flow conditions that are too low to be measured with a current meter. These portable devices are applied according to methods described in Buchanan and Somers $(1969$, p. 57) and Rantz and others (1982, p. 263).

The Field Office Chief is responsible for ensuring the correct selection and installation of artificial controls, with assistance from the Surface-Water Specialist as needed. The criteria used for selecting the type of artificial control include cost, channel and sediment characteristics, flow conditions, and range of discharge (Carter and Davidian, 1968, p. 3; Rantz and others, 1982, p. 15 and 348; and Kilpatrick and Schneider, 1983, p. 2 and 44).

When artificial controls are inspected, specific information pertaining to control conditions is written on the field note sheets to assist in analysis of the surface-water data. These notes include information on the condition of the control structure, scour or fill of the streambed immediately upstream from the control, vegetative growth, and debris on the control. Regular maintenance at artificial controls includes cleaning the control and approach section during each visit as needed, and running levels. When problems are encountered by field personnel, field notes are made to document the problem and the problems are corrected immediately if possible. If the control structure needs to be cleaned, gage readings are taken before any cleaning or repair of the structure is done and again after the cleaning or repair is completed and the flow conditions have stabilized. In situations where the scope of the problem prohibits field personnel from correcting the problem when first encountered, the Field Office Chief or the SW CBR Project Chief is notified so that the necessary corrective actions can be scheduled.

\section{Special Hydrologic Conditions}

\section{Floods}

Flood conditions present problems that do not occur on a regular basis. These problems can include difficulties in gaining access to a streamflow gage or measuring site because roads and bridges are flooded, closed, or destroyed. Debris in the streamflow can damage equipment and present dangers to personnel collecting the data. Rapidly changing stage or conditions requiring measurements to be made at locations some 
distance from the gage can create problems in associating a gage height to a measured discharge.

The District maintains a flood plan so that high-priority surface-water data associated with flood conditions are collected correctly and in a timely manner. The flood plan describes responsibilities before, during, and after a flood, field-activity priorities and informationreporting procedures. WRD Memorandum 00.12 provides policy and guidelines for timely documentation and reporting of flood events. The flood plan also serves as a central reference for emergency communications, including telephone numbers of key District and cooperator personnel, and numbers for accessing streamflow gages equipped with telemetry.

The Flood Coordinator is responsible for ensuring that the flood plan includes all appropriate information, including updated information. Currently, the SW CBR Project Chief is the designated Flood Coordinator; the Chief, HSDS, and the District Surface-Water Specialist are the alternates. The flood plan is reviewed annually, and updated when significant changes occur, by the SW CBR Project Chief, and Surface-Water Specialist. A copy of the flood plan is provided to all personnel in the HSDS and other individuals in the District who assist in surface-water activities. The Chief, HSDS, ensures that appropriate individuals receive a copy of the flood plan. The plan is to be kept with each person's field files. The Flood Coordinator and Field Office Chiefs ensure that individuals who receive a copy of the plan are proficient in the procedures in the flood plan.

During localized flooding within a Field Office area, the Field Office Chief coordinates flood activities. During a broader or statewide flood, the Flood Coordinator coordinates surface-water data-collection activities. Personnel not already in the field should contact the Flood Coordinator or Field Office Chief and be available to receive assignments. Employees who are already in the field should call the Flood Coordinator each morning and at the end of the day to provide discharge-measurement data and information on local conditions. The Flood Coordinator may be able to provide the following information to field personnel to help direct field work: current gage heights and times, priority needs, malfunctioning gages, description of area affected by flooding, location of storm and storm track, precipitation amounts, location of road closures, and the location of other field personnel. Personnel who arrive at a gaging station during high water are responsible for their personal safety, ensuring that all station equipment and measuring devices are safe and located above expected high-water crest, determining stage and measuring discharge, and telephoning results to the Flood Coordinator or Chief, HSDS. Personnel are to use methods discussed in Rantz and others (1982, p. 60) for determining peak stage at gaging stations.

District personnel follow policies and procedures documented in publications and memorandums when collecting surface-water data during floods. Techniques for current-meter measurements of flood flow are presented in Rantz and others (1982, p. 159-170). Procedures for identifying high-water marks for indirect discharge measurements are presented in Benson and Dalrymple (1967, p. 11). When discharge measurements are made a distance from the gaging station during changing stage, adjustments are applied to make measured discharge hydraulically comparable with recorded gage height as described in OSW Memorandum 92.09 and in Buchanan and Somers (1969, p. 54). When measurements are made some distance from the gaging station, the District policy is to establish temporary reference marks for noting the rate of stage change.

The Chief, HSDS, is responsible for reviewing District activities related to floods. This review includes seeing that guidelines and priorities identified in the flood plan are followed and that the guidelines appropriately address District requirements for obtaining flood information in a safe and thorough manner. If deficiencies are identified, the problem and possible solution are discussed with the Flood Coordinator and Surface-Water Specialist. Corrections are communicated to field personnel in writing and the flood plan is updated as necessary. Employees who have questions about particular policies or procedures related to flood activities or who recognize the need for additional training in any aspect of flood-data collection are to contact their Field Office Chief or the Flood Coordinator.

\section{Low Flow}

Streamflow conditions encountered during periods of low flow typically are much different from those during periods of medium and high flow and include braided channels and aquatic plant growth, which create poor measurement conditions. Low-flow discharge is measured to define the lower segment of the stage-discharge relation at gaging stations, to identify gains or losses of flow between the channel and ground-water system, and to evaluate other relations. Additionally, low-flow measurements are made to define the relation between low-flow characteristics of one basin and those 
of nearby basins so that flows can be estimated from the basin for which more data are available (OSW Memorandum 85.17 ).

In many situations, low flows are associated with factors that reduce the accuracy of discharge measurements. These factors include algae growth that impedes the free movement of current-meter buckets and the movement of large percentages of the flow in the narrow spaces between cobbles. When natural conditions are in the range considered by the field personnel to be undependable, the cross section is physically improved for measurement by removal of debris or large cobbles, construction of dikes to reduce the amount of nonflowing water, or other such efforts (Buchanan and Somers, 1969, p. 39). After the cross section is modified, the flow is allowed to stabilize before the discharge measurement is initiated. If the channel modification affects the stage at the gage, notes are to be made on the discharge measurement note and visit sheet to record gageheight readings before and after the measurement. District policy requires that gage height corresponding to zero flow be determined by field personnel for all wadable stations, where feasible. Gage height of zero flow generally is determined by measuring the elevation, referenced to gage datum, of the lowest point of the section control. The Field Office Chief will ensure that District personnel use appropriate equipment and procedures during periods of low flow and will review all droughtrelated data.

\section{Cold Weather}

Surface-water activities in the Wisconsin District include measuring stream discharge during cold weather. Cold temperatures, wind, snow, and ice can hinder data collection and can be dangerous to field personnel. Additional procedures are necessary to ensure employee safety when collecting streamflow data during periods of cold weather.

When the stream at the gaging station is affected by ice, discharge measurements made during complete or partial ice cover are useful for analysis and determination of flow during periods of ice-affected stage record. District personnel are required to follow procedures for discharge measurements under ice cover as described in Buchanan and Somers (1969, p. 42), which include procedures for discharge measurements made by wading or discharge measurements from cableways and bridges when debris and ice are in the stream. District personnel also follow procedures to collect winter streamflow data as presented in Rantz and others (1982, p. 124). Additionally, OSW Memorandum 84.05 provides guidelines on equipment for measuring flow under ice.

Equipment presently preferred by OSW for measuring discharge during slush-free conditions under ice cover is a Price AA current meter built with a Water Survey of Canada (WSC) winter-style yoke and a conventional metal-cup rotor. The pygmy meter also may be used (OSW Memorandum 84.05). After the effective depth of the ice cover is determined for a stream free of slush, District policy is to use the same criteria for Price AA or pygmy meter selection as for open-water flows (the Price AA meter is used where effective depths are $1.5 \mathrm{ft}$ or greater). Where slush ice is present, the metering equipment preferred by OSW has a WSC winterstyle yoke with a polymer rotor (OSW Memorandum 88.18). Although polymer rotors are not to be used during all other conditions (OSW Memorandum 90.01), the superior ability of the polymer rotor to shed slush ice and retard freezing in ice-covered streams is considered to be more important than the turbulent-flow-related inaccuracies associated with the rotor (OSW Memorandum 92.04). The OSW also considers the regular Price AA meters with conventional metal-bucket rotors to be acceptable for use in slush-free conditions if holes larger than those required by the WSC winter-style yoke can be cut through the ice (OSW Memorandum 92.04). The Fraiser vane ice meter also may be used under ice cover. The vanes do not become filled with slush ice as the cups of the Price AA meter often do. Other advantages of the vane ice meter are that the meter will fit in the hole made by the ice drill, the yoke and ice rod also serve as an ice-measuring stick, and the contact chamber of the vane meter can be rotated to any position.

The velocity distribution under ice cover is such that velocities are slower near the underside of the ice as well as near the streambed. The conventional $0.2-$ and 0.8-depth positioning method is recommended for effective depths of $2.5 \mathrm{ft}$ or greater and the 0.6-depth positioning method is recommended for effective depths less than $2.5 \mathrm{ft}$. Ratios of point velocities at various depths need to be defined when ice measurements are made to determine whether any coefficients are necessary to convert the velocity obtained by the 0.2 - and 0.8-depth method or the 0.6-depth method to the mean velocity. The average of the velocities obtained by the 0.2 - and 0.8-depth method usually is an acceptable mean velocity, but a coefficient of 0.92 typically is applied to the velocity obtained by the 0.6 -depth method. When the velocity is measured, the meter is 
kept as far upstream as possible to avoid the effect of the vertical pulsation of water in the hole. Exposure of the meter to cold air during the measurement should be minimized by keeping the meter submerged. The meter must be free of ice when the velocity is being determined.

All measurements made during ice cover are required to be checked by a checker or the Field Office Chief following winter field trips and annually as part of a surface-water records review. The computer discharge calculation program QCOMP may be used to compute and check measurements. The Field Office Chief or project chief will determine whether a two-person crew will be used for winter field trips for safety or other reasons during unusual weather conditions or for specific sites.

\section{PROCESSING AND ANALYSIS OF STREAMFLOW DATA}

The computation of streamflow records involves the analysis of field observations and field measurements, the determination of stage-discharge relations, the adjustment and application of those relations, and the systematic documentation of the methods and decisions that were applied. Streamflow records are computed and published for each gaging station annually. This section of the QA Plan includes descriptions of procedures and policies pertaining to the processing and analysis of data associated with the computation of streamflow records. The procedures followed by the District coincide with those described in Rantz and others (1982) and in Kennedy (1983).

\section{Processing of Real-Time Streamflow Data}

Real-time streamflow data in Wisconsin are served from computers located in Middleton and maintained by the District. The National Water Information System-Web (NWIS-W) software is used to conform to USGS standards for presentation format. The District's Web pages at http://wi.water.usgs.gov provide access to real-time data on the Internet and other pertinent information, including Web page links to other USGS offices, related water-resources agencies, the NWS, weather data, and other databases.

The District's Web pages are maintained by the Webmaster, Computer Specialist, and Surface-Water Specialist. A necessary and critical element in maintain- ing accurate streamflow records on a real-time basis is the need for rating analysis and shift application as soon as is practical after a discharge measurement has been made. The Wisconsin District's policy is that rating analyses and shift applications will be performed by using the following procedures for data disseminated on the District's public Web page.

During normal flow conditions and for sites determined to be non-critical from a water-management perspective, District policy is that discharge measurement notes be reviewed and the current shift applied in the data processing system (ADAPS) within 10 workdays following completion of the field trip. During major flooding and depending on the site and situation, earlier measurements and shifts should be called in daily from the field to the Flood Coordinator. This is required if shifts have a substantial effect on peak flows and pertains especially to sites co-located with NWS floodforecast points and U.S. Army Corps of Engineers sites. During floods, discharge measurements may be needed at specific locations to help define the upper end of the rating. At the same time, an equipment malfunction or damage from flood water at a site might make it necessary to divert personnel from making high-flow measurements to making equipment repairs. The order of priorities for the allocation of resources during a flood generally are to

1. Maintain or repair equipment to avoid or minimize loss of data,

2. Sample at or service water-quality sites that are event-dependent to meet the objectives of study,

3. Make flood discharge measurements to define rating based on need for measurements, timing of peaks, urgency, and availability of field personnel.

Priorities for measurements at gaging stations and CSG sites are listed in the District Flood Plan. Questions about priorities should be directed to the Flood Coordinator, Surface-Water Specialist, or Chief, HSDS.

\section{Review of Real-Time Streamflow Data}

Real-time streamflow data that are disseminated on the public Web page must be reviewed frequently to ensure their quality and to prevent the distribution of erroneous information (WRD Memorandum 99.34). The District uses both automated and manual review procedures to meet this objective. 
Automated procedures that have been implemented by the District include the setting of minimum and maximum threshold values for stage and discharge and their rates of change. If exceeded, these settings will initiate warnings of potential errors that will be delivered by email to the appropriate District personnel. The SurfaceWater Specialist and Database Manager are the District personnel designated to receive and act on these messages. Detailed procedures used in the Wisconsin District for processing real-time streamflow data are presented in appendix 2.

In addition to the automated procedures, WRD Technical Memorandum 99.34 requires frequent and ongoing screening and review of Web data, including at least daily review of hydrographs during normal hours of operation. The District also requires that real-time streamflow data be reviewed regularly for accuracy and (or) missing data. This task usually is done daily each morning during normal working hours, but the frequency may vary depending on current flow conditions or on whether the sites are critical to water-management agencies and the NWS. The frequency of reviews is increased and extended beyond normal working hours, including weekends, during times of major flooding. The SW CBR Project Chief, Surface-Water Specialist, and Database Manager are responsible for these reviews. Field offices also are responsible for reviewing the sites within their operational jurisdiction. Weekly gage-height plots are generated for stations that have been requested by the field offices, technicians, and project chiefs. The stations with automatic samplers also have sampling times plotted on the graph. For project sites, this review is the responsibility of the project chief.

\section{Error Handling}

Two general types of errors are associated with streamflow data that are delivered by the real-time system and disseminated on the Internet. The first are persistent problems that typically are associated with some type of equipment failure in data collection or transmission, but also could be related to ice effects. Because of the nature of these problems, they generally occur on a continuing basis for more than a single recording interval. The second are intermittent problems, which often are the result of a data-transmission error. These typically are present as missing data, a zero, or an unreasonably large value. When plotted in a hydrograph, these erroneous values are accommodated by a forced expan- sion of the $y$-axis of the plot, which renders the other data indiscernible. If these errors occur, they are corrected as soon as possible as other work priorities allow. On a daily basis, the Database Manager attempts to retrieve any data that have not arrived. Some failed data retrievals are initially ignored, but are called back automatically by the computer after a few hours. Action is taken only if the automatic callbacks are not getting through or if there is urgent need for the data. The responsible technicians and project chief are notified of any sites that are not responding or if repairs are needed.

A feature in the computer program DECODES is used at sites to filter out values that are obviously in error and outside a specified range so that they are not stored in ADAPS. Several automated notifications are sent by e-mail for data not retrieved, incomplete retrievals, date errors, and various other problems. "Bad" values also are manually removed from the tables used to generate the Web pages. If warranted, Field Offices or responsible technicians are notified to edit the unit values in ADAPS.

\section{Data Qualification Statements}

WRD Technical Memorandum 95.19 requires that streamflow data that are made available on the Web should be considered provisional until the formal review process has been completed. To ensure that everyone who accesses data on the Web is aware of this fact, data qualification statements are included at key locations with a clickable heading "Provisional Data Subject to Revision" on all real-time data pages.

\section{Measurements and Field Notes}

The gage-height information, discharge information, control conditions, and other field observations written by personnel on the measurement note sheets and other field note sheets form the basis for records computation for each gaging station. Measurements and field notes that contain original data are required to be stored indefinitely (Hubbard, 1992). Measurements and other field notes for the water year that is currently being computed are filed in an annual computation folder for each station. Measurement field notes for previous water years are backfiled by each Field Office.

Discharge measurements made during floods, during ice cover, that define extreme low flow or large shifts from the rating, that are sent to cooperating agen- 
cies, and that are used to develop the rating are required to be checked by reviewing the mathematics and other items listed in Kennedy (1983, p. 6-7). After the discharge measurements are checked, field personnel are expected to enter the measurement information and remarks into the current USGS database within 2 weeks of returning from the field. A printout of the measurement summary (Form 9-207) is included in the primary folder for the station records. It is the responsibility of the individual computing the records for each station to ensure that the measurement note sheets are correct, that the information stored in the computer files agrees with that on the measurement note sheets, and that an updated printout of the measurement list is contained in the folder.

\section{Continuous Gage-Height Record}

Surface-water gage-height data are collected as continuous record (hourly, 15-minute, or 5-minute values, for example) in the form of electronic transmissions by telephone, values stored in electronic data recorders, digital punches on paper tape, or pen traces on paper by primary and backup recorders. Streamflow records are computed for most stations by converting gage-height record to discharge record through application of stage-discharge relations. Ensuring the accuracy of gage-height record is, therefore, a necessary component of ensuring the accuracy of computed discharges.

Gage-height record is assembled for the period of analysis in as complete a manner as possible. Periods of inaccurate gage-height data are identified, then corrected (see the section "Datum corrections, gage-height corrections, and shifts"), or deleted as appropriate. Items included in the assembly of gage-height record and procedures for processing the data are discussed in Kennedy (1983, p. 6), and Rantz and others (1982, p. 560 and p. 587).

Data are transmitted by telephone (landline or cellular) for almost all stations or by satellite data-collection platforms for a few stations and entered into the ADAPS computer database through DECODES. These data are retrieved by automated computer retrieval programs. Data from storage modules or other forms of storage are entered into ADAPS from field computers following a data-collection field trip. Raw data files are maintained unaltered for future reference. Stage data stored in the computer files are used for computing surface-water records and are compared closely with field observations, including observer readings. Observer readings are maintained in the designated computation folder by station. All stage data are reviewed by the hydrographer after entering data and before computing the record.

Because data are provided on a near real-time basis to the public on the District World Wide Web homepage, District policy is to review the data daily by visually scanning the hydrographs for periods of missing, incomplete, or obviously questionable data. The Field Office Chief is responsible for ensuring that the gageheight data received from stations are reasonable.

\section{Records and Computation}

Each Field Office is responsible for maintaining surface-water station files. The station record file includes the current computation folder with the primary printout, rating and discharge measurements, station description, the historical-data backfile, and the station history folder. These files are located in an easily accessible area and clearly labeled with the station name and identification number.

Record computation is done on a continuing basis to improve the accuracy of real-time and provisional data, and to minimize the work effort after the end of the water year. The hydrographer assigned to the gaging station is responsible for computing the record. The record is then checked independently by staff other than the individual who computed the record to determine whether the record was computed as documented and to detect any possible errors in data entry or analysis. The SW CBR Project Chief, Field Office Chiefs, and other project chiefs will review the final checked records to ensure compliance with USGS policies and procedures prior to publication of the data.

\section{Procedures for Computing and Checking Records}

Procedures for ensuring the thoroughness, consistency, and accuracy of streamflow records are described in this section of the QA Plan. In the Wisconsin District, a record computation checklist maintained in each current station folder is used to track the steps completed in the computation process. The goals, procedures, and policies presented in this section are grouped in association with the separate components that are included in the records-computation process. 


\section{Gage Height}

The accuracy of surface-water discharge records depends on the accuracy of discharge measurement, the accuracy of rating definition, and the completeness and accuracy of the gage-height record (OSW Memorandum 93.07). Computation of streamflow records includes ensuring the accuracy of gage-height record by comparing gage-height readings made by use of independent reference gages, comparing inside and outside gages, examining high-water marks, comparing the redundant recordings of peaks and troughs by use of maximum and minimum indicators, examining data obtained at CSGs, and confirming or updating gage datums by means of leveling surveys.

Records computation includes examination of gage-height record to determine if the record accurately represents the water level of the body of water being monitored. Additionally, it includes identifying periods of time during which inaccuracies have occurred and determining the cause of those inaccuracies. When possible and appropriate, inaccurate gage-height record is corrected. When corrections are not possible, the erroneous gage-height data are removed from the set of data used for streamflow records computation.

For stations having more than one recorder collecting gage-height record, one is designated as the primary recorder and the other is the backup recorder. For example, at a station that has a data-collection platform (DCP) for satellite transmission and an analog recorder, the DCP is the primary recorder and the analog recorder is the backup recorder. The purpose of the backup recorder is to verify the gage-height data collected by the primary recorder, to provide stage record should the primary recorder malfunction, and provide information that may not be discernible from the digital record. In the case of bad or missing record, if gage-height record is available and used from backup recorders, it is copied to the primary data descriptor and noted on the primary computation printout and in the station analysis. A unitvalue plot of the gage-height record should be made to check for periods of questionable record. When a correction is made, notes describing the basis for the correction and how the correction was applied will be made on the primary sheet and station analysis. Also included on the primary printout are any computation notes about the accuracy of the record, such as ice-affected or missing gage-height data. The hydrographer computing the record is responsible for ensuring that the final record contains all the corrections needed, and record checkers verify that the correct procedure was followed.

\section{Levels}

Errors in gage-height data caused by vertical changes in the gage or gage-supporting structure can be measured by running levels. Gages can be reset or gage readings can be adjusted by applying corrections based on levels (Kennedy, 1983, p. 6).

Procedures for computing records for each station include ensuring that the front sheet has been completed for each set of levels, checking the level notes for errors, ensuring that information is entered correctly in the historical level summary, and ensuring that information was applied appropriately as datum corrections. The individual computing the records is required to check field notes for indications that the gages were reset correctly. The individual computing the records makes appropriate adjustments to the gage-height record by applying datum corrections. All changes are noted in the station analysis and on the primary printout.

\section{Rating}

The development of the stage-discharge relation, also called the rating, is one of the principal tasks in computing discharge records. The rating is usually the relation between gage height and discharge (simple rating). Ratings for some special sites involve additional factors, such as rate of change in stage or fall in slope reach (complex ratings) (Kennedy, 1983, p. 14). District personnel are to follow procedures for the development, modification, and application of ratings that are described in Kennedy (1984) and guidelines pertaining to rating and records computation that are presented in Kennedy (1983, p. 14) and in Rantz and others (1982, chap. 10-14 and p. 549).

For each gaging station, the most recent rating table or graph can be obtained by using standard USGS computer software or by retrieving a paper copy from either the field folder or the Field Office station file, or by asking the Field Office Chief or Project Chief. A copy of the most recent rating table shall be kept at each gaging station and in current field and office folders. A graphical plot of the most recent rating will be kept in the office file. Old ratings will be kept in station backfiles. All high-stage measurements should be plotted and numbered on the graphical rating. New discharge rating curves and tables are developed and reviewed in the 
originating Field Office before being put into use. The hydrographer enters the rating into the computer and the checker verifies that the rating was entered correctly. Complex rating curves should be reviewed by the Project Chief or Surface-Water Specialist. All ratings must be checked before copies are sent outside the office.

The goal of policies and procedures pertaining to ratings is to promote efficiency and accuracy in the development and documentation of ratings. It is the responsibility of the individual working the station records to ensure that measurements for the current year and all high-water measurements for the station are plotted on the current work plot of the rating. Generally, changes in the stage-discharge relation that tend to be temporary are addressed through the use of variablestage shifts. It is left to the discretion of the hydrographer working the station records to determine whether changes in the relation are addressed with shifts or warrant the introduction of a new rating. Changes in the stage-discharge relation that are relatively stable generally warrant the introduction of a new rating. It is the responsibility of the individual computing the records to fully develop the new rating, enter all input values and offsets into the computer using standard USGS software, and to plot the new rating with the measurement data. It is the responsibility of the individual checking the station records to ensure that the rating input points and offsets agree with available measurement data. The checker has the latitude to disagree with the scope and shape of the new rating and with the original decision on whether or not to introduce a new rating, however, it is the responsibility of the checker to discuss these disagreements with the individual that worked the station records. The two must come to a consensus on the appropriate rating to use. If a consensus is not reached, it is their responsibility to present the matter to the Field Office Chief or Project Chief, who will make a final determination.

\section{Datum Corrections, Gage-Height Corrections, and Shifts}

A correction applied to gage-height readings to compensate for the effect of settlement or uplift of the gage is measured by level surveys and is called a "datum correction" (Kennedy, 1983, p. 9). Datum corrections are applied to gage-height record in terms of magnitude (feet) and time (when the datum change occurred). In the absence of any evidence indicating exactly when the change occurred, the change is assumed to have occurred gradually from the time the previous levels were run, and the correction is prorated with time (Rantz and others, 1982, p. 545). Datum corrections are applied when the magnitude of the vertical change is greater than $0.015 \mathrm{ft}$.

A correction applied to gage-height readings to compensate for differences between the recording gage and the base gage is called a "gage-height correction" (Rantz and others, 1982, p. 563). These corrections are applied in the same manner as datum corrections by use of the same standard USGS computer software. Gageheight corrections are applied so that the recorded data agree with the base-gage data. These corrections are applied when the gage-height difference between the recording gage and the base gage is equal to or greater than $0.02 \mathrm{ft}$, or for as small a difference as $0.01 \mathrm{ft}$ when warranted due to low-water conditions when the percent difference from the rating is excessive.

A correction applied to the stage-discharge relation, or rating, to compensate for variations in the rating is called a shift. Shifts reflect the fact that stage-discharge relations are not permanent but vary with time, either gradually or abruptly, because of changes in the physical features that form the control at the gaging station (Rantz and others, 1982, p. 344). Shifts can be applied to vary in magnitude with time and with stage (Kennedy, 1983, p. 35). Shift curves are developed from the existing log rating-curve plots and transferred to form arithmetic variable-shift diagrams to be used in the shift application process. The stage-shift program should also be used for time-only shifts. All shifts must be documented in the station analysis and entered into the measurement summary file. Care should be taken to explain why a shift occurred as well as how and when the shift was applied. All shifts are entered and reviewed in the computer using current USGS NWIS software. A shift paragraph, a narrative that describes how shifts-by-stage were distributed, is included in each gaging station's station analysis.

Datum corrections, gage-height corrections, and shifts for each station are entered in the standard USGS data-processing software (ADAPS), and are stored as finalized data upon completion of the District's recordscomputation process. The individual who works the station records ensures that recorded gage heights and computed discharges represent a logical and smooth transition between water years. Datum corrections, gage-height corrections, and shifts are discussed in the station analysis, and associated copies of the variableshift diagram and computer-generated shift analysis 
indicating how the shifts were distributed are attached to the station analysis to be included as part of the permanent record. This documentation is maintained indefinitely for future reference.

\section{Hydrographs}

A discharge hydrograph is a plot of daily mean discharges versus time. The date is aligned with the horizontal axis and the discharge is aligned with the logarithmic vertical axis. In the process of computing station records, this hydrograph is a useful tool for identifying periods of erroneous information, such as incorrect shifts or datum corrections. Additionally, hydrographs are helpful when estimating discharges for periods of undefined stage-discharge relation, such as during backwater or ice conditions, and in estimating discharges for periods of missing record.

Information recorded on the hydrograph for each station includes the station name, station number, water year, date the hydrograph was plotted, plots of measurements and inspections, periods of missing record, estimated discharges for days of missing record, periods of ice effect, and estimated discharges during periods of ice effect. To assist in the estimation of discharges during periods of ice effect and missing record, precipitation, air-temperature, and water-temperature data are also superimposed on the hydrograph. If other station records are plotted on the same hydrograph, use of a different color for each station is a practical way to indicate the record at each station. Notes of climatic and hydrologic conditions observed by field persons and observers may also be transferred to the hydrograph, and written vertically on the day to which the note applies. All hydrographs are plotted on a pre-printed standard form so that a plot for one station can be compared directly to that of another station. The individual that computes the station records is responsible for completing the hydrograph. The individual that checks the records ensures that the hydrograph is complete and correct. Hydrographs are an important analysis tool and are used to check computed record by comparison with nearby or similar stations.

Hydrograph comparison is a component of records computation for each station. Hydrograph comparison, further described in Rantz and others (1982, p. 575) is an effective means for evaluating the validity of shift, datum, or gage-height correction applications, identifying periods of faulty gage-height data, and estimating discharges for periods of missing record or periods of no stage-discharge relation. After records are computed, checked, and finalized, each hydrograph is filed in the station folder and maintained indefinitely for future reference.

\section{Station Analysis}

A complete analysis of data collected, procedures used to process the data, and the logic upon which the computations were based is documented for each year of record for each station to provide a basis for review and to serve as a reference in the event that questions arise about the records at some future date (Rantz and others, 1982, p. 580). Topics discussed in detail in the station analysis include equipment, gage-height record, levels, datum corrections, rating, determination of discharge, range of discharge and measurements, cause of shifts and how shifts were applied, extremes, and remarks. The station analysis is written by the individual who prepares the record for the water year, who is generally the field person assigned to the gaging station. The station analysis should be written clearly and concisely and should include all information pertinent to final streamflow determinations. A District-prepared script program (SA.TABLE) is available for tabling gage-height corrections, discharge measurements, and variable shifts to assist in the preparation of station analyses. Included with the hard copy of the station analysis are all graphs of variable-stage shift diagrams, a printout of the shift analysis, a printout of the computer-generated year-end summary, and attached SA.TABLE.

When the record has been computed, a person is assigned to check the record and the station analysis. This person is responsible for the accuracy of the entire record and station analysis. By signing the station analysis, the person certifies that the record with the supporting information is complete and accurate. If differences of opinion arise between the preparer of the record and the checker, the order of responsibility for resolving differences is: (1) Field Office Chief, (2) Project Chief (3) Surface-Water Specialist, and (4) Chief, HSDS. The final copy of the station analysis is filed in each current water-year station folder to be maintained indefinitely. These station folders are maintained in each Field Office and a complete set of history folders is maintained in the District Office. An electronic copy of all station analyses is also maintained by the District Hydrologic Assistant on the current computer system under one directory called STATIONANALYSES. The hard copy of the analysis, signed and 
dated by the writer and the checker, is considered the permanent document for the station file.

\section{Winter Records}

Computing records that represent winter conditions at gaging stations involves procedures that are not applicable to records that represent conditions at other times of the year. The formation of ice in stream channels or on section controls affects the stage-discharge relation by causing backwater; the effect varies with the quantity and nature of the ice, as well as with the discharge (Rantz and others, 1982, p. 360). During some conditions the recorded gage-height data may be accurate, although the actual stage-discharge relation may be undeterminable and unstable. An example of this condition is when surface ice forms on the stream, but the stilling well remains unfrozen and the water level in the stilling well represents the backpressure caused by the ice in the channel. During other conditions the recorded gage-height data may be inaccurate, resulting in periods of missing gage-height record. An example of the latter is when a stilling well or the intakes to the stilling well are frozen.

The individual computing the station record is responsible for identifying ice-affected periods, documenting those periods in the station analysis and on the hydrograph, and estimating daily mean discharges for the period. The individual also identifies periods of faulty or missing gage-height record, documents those periods in the station analysis and on the hydrograph, estimates daily mean discharges for the period, and enters those estimates in the daily values computer file. That individual identifies the specific unit values that should be considered faulty record and should be deleted from the unit-values computer file; the faulty period is clearly indicated on the primary computation sheets. The individual who checks the winter records is responsible for ensuring that the determinations of iceaffected periods, periods of faulty gage-height record, and estimated daily mean discharges are correct. If the checker is in agreement with the periods of record that are faulty, the hydrographer is responsible for deleting the faulty unit values from the unit-values computer file. The checker is responsible for discussing any disagreements with the individual who computed the records. If the two cannot reach a consensus on corrective actions that address the disagreement, the Field Office Chief or Project Chief is responsible for making the final determination. In general, the checker is responsible for making corrections to the data files and documentation; for more extensive broad-scale changes, however, the individual who computed the record modifies or corrects the station records.

Some streams remain open and free from ice effect most of the time as a result ground water discharging into the stream, flow of heated water from power plants or similar facilities into the stream, or warmer outflows released from reservoirs. If applicable, the hydrograph from one of these stations is used as a guide in estimating winter discharges at nearby ice-affected stations. At other stations, ice effect is more intermittent or infrequent; when estimating the discharge for these stations, the recorded gage-height data are carefully examined, and appropriate consideration is given to the open-water part of the day.

Individuals that work station records for winter periods use a combination of recorded gage-height data, discharge measurements, precipitation and temperature data, and other environmental information that may be available. Although ice-affected discharge measurements are truly representative only for a specific time at a site, the measurements are helpful for determining a general range of discharges, from which daily means for selected time periods can be estimated. Unit-value plots are used to identify streamflow patterns associated with the occurrence of ice. Hydrograph comparison with nearby stations is useful in estimating daily mean discharges. Nearby stations on streams that tend to remain free of ice are particularly useful. The discharge is estimated on the hydrograph from comparison with a nearby, preferably open-water station, and the temperature graph. If daily discharges are estimated on the hydrograph, they will be shown on the primary printout and entered into the computer daily values table. Periods of estimated daily discharges are identified on all daily value tables with an "e." All periods of estimated daily discharges are shown on the hydrograph as dashed lines. Generally, records for days for which discharges are estimated are considered poor.

\section{Furnished Records}

Some surface-water data collected under the supervision of other agencies, organizations, or institutions are received by the District office and published in the annual data report. Daily mean discharge data provided by other agencies are reviewed before publication by the same processes used for USGS data (WRD Memorandum 85.129) The evaluation of these records often 
includes occasional discharge measurements to verify the ratings. As a minimal check, hydrographs are compared with those from nearby stations operated by the District. If errors in the data are suspected, the furnishing agency is contacted to determine if an error has been made. Daily mean discharge data are taken from the supplied printed copy and entered into the database. Another type of data comes from cooperating agencies supplying daily, or most commonly month-end reservoir contents. Data tables and correspondence from the furnishing agency are maintained in the station folder for future reference. The agency that furnished the data is identified and given credit in the annual report when the data are published.

\section{Daily Values Table}

With few exceptions, a discharge value is determined and stored for each day for each gaging station operated by the WRD. The daily values table generated by use of the records-computation software contains the discharge values that are stored for each day of the water year. It is the responsibility of the individual that computes the records to ensure that the daily values table, which includes those values stored in the daily values computer file, contains the correct data. It is also that individual's responsibility to ensure that the correct values stored in the daily values table also are contained in the hydrograph, working primaries, and the publication-ready manuscript. The table is checked against the computed primary and the estimated record to ensure that the proper daily values have been stored. The individual checking or reviewing the records prints a new copy of the daily values table if any daily values are updated in the computer as a result of the check or review. The printed daily values table is filed in the folder for each station. The printed table is checked against the final manuscript prior to publication of the annual data report, and against the daily values stored in the computer prior to marking the values in the computer as final.

\section{District Checkoff List}

The District uses a gaging-station record-computation checklist to track the status of record computation for each station and to ensure that errors do not occur by omitting the necessary procedural steps. Another use for the checklist is to let the reviewer know whom to contact if questions arise later. A checklist for each sta- tion showing the status of record computation is available in each Field Office and is kept in the record computation folder throughout the whole computation and review process. Both the person computing the initial record and the person checking the record initial each of the specific phases of the records computation process completed. When the record is reviewed, the completed computation checklist is backfiled along with the other computation data in the station folder.

\section{Review of Records}

After streamflow records for each station have been computed and checked, records for at least 20 percent of the District's gaging stations are reviewed by a team of experienced individuals from the various field offices and District Office. The goal of the review is to ensure that proper methods were applied throughout the process of obtaining the surface-water data and computing the record. To promote consistency and reduce the potential for systematic errors, records will be exchanged among field offices and a different individual that computed and checked the record will conduct the review. It is the responsibility of the Chief, HSDS to ensure that any deficiencies identified in the review are corrected and that actions are taken to prevent the recurrence of those deficiencies.

If procedural errors are noted, the appropriate Field Office personnel are contacted and the record is discussed. This first communication usually results in resolution. Occasionally, a record is returned to the originating Field Office for rework, with deficiencies noted in writing. After the deficiencies are corrected, the record is returned to the District for processing. Disputes are officially resolved by, in order, the Field Office Chief, Project Chief, or Chief, HSDS.

\section{Crest-Stage Gage Data}

Records for CSGs are computed with goals and procedures similar to those for other gaging stations. The field notes are examined for correctness and accuracy. Peak stages recorded by CSGs are cross referenced with other available information; the dates of the peaks are determined by analyzing available precipitation data and peak data from recording gages within the same basin or from nearby basins.

A discussion of the policies and procedures used for field aspects of collecting data at CSGs is included 
in this report in the section "Collection of Stage and Streamflow Data." The discussion in this section describes the analysis and office documentation of crest-stage data. This section does not pertain to data collected at CSGs installed solely for the purpose of confirming peak stages at sites where pressure-transducer gages are used.

At sites where CSGs are used to compute peak discharges, an initial stage-discharge relation, or rating, is developed for the site by direct or indirect high-water measurements. The rating is verified or adjusted on the basis of subsequent direct or indirect high-water measurements.

For each station, a list of all measurements is maintained and each measurement is assigned a chronological number. Ratings, consisting of a graph and digital table, are maintained and updated in a manner similar to that used for a daily discharge station. A list of peak gage heights is maintained for each station and verified by checking against field notes when the record is worked. Current station descriptions and a summary of levels are maintained in the office station folder as well as in electronic format. A brief station analysis is written each year describing how the annual peak was computed, identifying which rating was used, the type of flow condition, how the dates of the peaks were determined, and explaining any shift that may have been applied. Computing peak discharges and updating the manuscript for each crest-stage gaging station is the responsibility of the hydrographer assigned to the station. Computations are checked by another experienced individual and reviewed by the project chief.

The Field Office Chief assigns stations to field personnel for the collection of data and ensures that annual peaks at CSGs are computed correctly. When incorrect actions or procedures are identified during review, he discusses those changes with the person who computed the record and problems are remedied by providing oneon-one training. A current list of annual peaks is maintained in the station folder for review purposes (OSW Memorandum 88.07). The Hydrologic Assistant in HSDS is responsible for updating the NWIS Peak-Flow File promptly after the peak data have been finalized, which is reviewed by the project chief.

\section{COLLECTION OF SEDIMENT DATA}

As part of the Collection of Basic Records (CBR) Program, surface-water activities in the District include the collection, analysis, and publication of sediment data. District operations adhere to policies related to sediment data collection set forth by the OSW. Responsibility for the sediment discipline was transferred from the Office of Water Quality (OWQ) to the OSW in 1985 (OSW Memorandum 92.08). The policies and procedures related to sediment followed by the District are described in selected WRD publications and in memorandums issued by OSW, OWQ, and WRD. Techniques adopted by the USGS and followed by this District are presented in three publications of the series "Techniques of Water-Resources Investigations of the U.S. Geological Survey" (TWRI):

Book 3, Chapter C1-“Fluvial Sediment Concepts" by H.P. Guy (1970),

Book 3, Chapter C2-"Field Methods "for Measurement of Fluvial Sediment" by T.K. Edwards and G.D. Glysson (1999),

Book 3, Chapter C3-“Computation of FluvialSediment Discharge" by George Porterfield (1972).

A summary of memorandums issued since 1971 related to sediment and sediment transport is provided in OSW Memorandum 92.08. A summary of documentation that describes instrumentation and field methods for collecting sediment data is provided in OSW Memorandum 93.01.

\section{Sampling Procedures}

Field methods for sediment sampling are documented in Edwards and Glysson (1999). District personnel collect depth-integrated suspended-sediment samples using the single vertical method, and the Equal Width Increment (EWI) method. Automatic pumpingtype samplers are commonly used at gaging stations. For installation and use of automatic pumping-type samplers, the District follows the criteria described in Edwards and Glysson (1999).

Occasionally, observers are contracted to collect sediment samples at sediment stations. Normally, these samples are depth-integrated single-vertical samples collected near midstream. Training in sampling techniques and safety is provided to the observers by USGS personnel prior to sample collection. USGS personnel concurrently collect single-vertical samples and crosssection samples to verify accuracy of single-vertical samples. The District Sediment Specialist or a designated technician is responsible for scheduling and providing training for sediment-collection activities in the District. This individual establishes whether or not cor- 
rect procedures are being used by periodically accompanying personnel on sampling trips to review procedures and by reviewing results of QA replicate samples.

Field methods for sediment sampling are documented in Edwards and Glysson (1999) and OSW Memorandum 93.01. Water samples obtained for the analysis of sediment concentration and particle size are not composited (OSW Memorandum 93.01 and OWQ Memorandum 76.17). The cone splitter is used for sample splitting (OWQ Memorandum 80.17).

Policy for the collection and publication of bedload data is provided in OSW Memorandum 90.08. It is the responsibility of the field personnel to select the procedure that is optimal for the local condition. Bedload samples are analyzed individually in some situations and as a composite in others. Until sampling variability for a particular site is understood by those analyzing the data, all samples are required to be analyzed individually.

The individual in the District responsible for scheduling sediment-collection activities at specific sites is the Sediment Specialist or project chiefs of other sediment-data-collection projects. The District Sediment Specialist is responsible for ensuring that District personnel use correct procedures to collect sediment data. This individual establishes whether or not correct procedures are being used by performing a site trip with each person and observing techniques used, by discussing procedures and problems at meetings held each year, and by reviewing sediment records. Answers to questions from District personnel concerning sedimentsampling techniques are provided by the Sediment Specialist or 004 Project Chief.

\section{Field Notes}

District personnel are required to fill out note sheets each time a site is visited for the purpose of sediment sampling. The employee completes the note sheet in its entirety before leaving the site. Original observations written on the note sheets are not to be erased; data are corrected by drawing a line through the original observations and writing the correct information near the original value. The goal of placing information on the field note sheet is to describe the equipment and methods used during the site visit as well as to describe relevant conditions or changes (OSW Memorandum 91.15). For each site visit, information included on the field note sheet includes, at a minimum: site identifica- tion, field personnel name(s), date, time, sampling equipment, method, type of sample collected (concentration/sand-fine break), description of sampling points, and project account number. Additional documentation may include flow, weather, and relevant hydrologic conditions or changes. Upon completion of each field trip, field notes are placed in the site folder and are reviewed during record processing by the Sediment Specialist.

\section{Equipment}

Care and maintenance of the sediment-data-collection equipment are the responsibility of the field personnel who use the specific equipment. Parts replacement and repair of damaged equipment are accomplished by returning the equipment to the District Sediment Specialist or the designated technician. Field personnel or the project chief are responsible for ensuring that appropriate equipment is used at all sampling sites. Sampling equipment is selected on the basis of constituents that are being investigated, the type of analyses to be performed, and on the site conditions, such as velocity and maximum depth of water, to ensure that design limitations of the equipment are not exceeded. The District follows equipment-design criteria and guidelines referenced in OSW Memorandum 93.01 and Edwards and Glysson (1999).

\section{Sample Handling and Storage}

The quality of sediment data provided by a sediment laboratory is affected by the quality of the samples received from the field (Knott and others, 1992, p. 2). District personnel are required to prepare sample labels, analysis instructions, and sample documentation according to guidelines presented in Knott and others (1993). Samples are stored temporarily in a refrigerator until they are sent to a laboratory for analysis.

\section{Special Hydrologic Conditions}

\section{High Flow}

High-flow conditions at most streams, unless the streams are subject to the effects of backwater, are associated with high-energy conditions. The sediment load and particle sizes associated with high flows are significant factors in sediment studies performed by the Dis- 
trict. To ensure that field personnel are aware of their responsibilities in obtaining sediment samples at appropriate sites during high-flow conditions, required samples are scheduled to be collected during typical highflow periods. The project chief, project field coordinator, or designated technician is responsible for ensuring that sediment samples are obtained during opportunities provided by high-flow conditions. The field person is responsible for ensuring that the proper sampling equipment and methods are used during high-flow conditions. High-flow conditions can create dangerous sampling conditions and all field personnel must ensure their personal safety (refer to section titled "Safety"). The District Sediment Specialist is responsible for providing answers to District personnel who have questions concerning high-flow sampling equipment or sampling procedures.

\section{Cold Weather}

Sediment-sampling activities in the Wisconsin District include obtaining samples during periods of subfreezing temperatures. During cold-weather conditions, field personnel should take every precaution to ensure their personal safety. Additionally, field personnel should attempt to ensure that equipment is not damaged by floating slabs of ice and that nozzles are not clogged with ice crystals.

When floating slabs of ice pose the danger of damaging sampling equipment, such as during spring breakup, field personnel may manage only to obtain surface samples between the floating slabs of ice (Edwards and Glysson, 1999). The procedure is noted on the field note sheet and sample label. When anchor ice and frazzle ice are present, it may be necessary to move the sampling equipment quickly through ice crystals to avoid clogging the nozzle. This procedure is also noted on the field note sheets and sample label.

\section{Site Documentation}

A station description is prepared for each new sediment-sampling site. At sampling sites where streamflow-gaging activities occur, the description of sediment activities is included in the streamflow-gaging-station description. A list of elements included in each station description, along with an explanation of the items included with each element, is presented in the attachment to OSW Memorandum 91.15. At sites where sediment samples are collected but other streamflow data are not, the station descriptions are structured similarly to those for streamflow-gaging stations, and contain similar information (Kennedy, 1983, p. 2). Station descriptions are included in the field folder and are maintained in the office files. Each description includes specific information explaining where the sediment samples are to be collected and what method is to be used.

Field personnel are responsible for ensuring that field copies of station descriptions are kept current. Instructions for sediment sampling include a description of observer and field personnel responsibilities, sampling frequency, sampling location, and other pertinent information required to ensure proper sample collection and processing. At sites where sediment samples are collected periodically but the site is not a gaging station and a daily sediment record is not computed, station location and pertinent geographic information are recorded on the standard station header form. At the periodic sediment sites, sampling instructions are prepared in the same manner as that for water-quality sampling instructions. Sampling instructions are included in the field folder and are maintained in the office files. For all sampling sites, a log of sampling activities and laboratory submittals is kept as part of the station's folder.

\section{PROCESSING AND ANALYSIS OF SEDIMENT DATA}

Sediment and associated streamflow data are compiled to produce sediment records for specific sites. Data processing of periodic measurements consists of four steps: tabulation, evaluation, editing, and verification (OSW Memorandum 91.15). The District follows the considerations and guidelines presented in Porterfield (1972), Guy (1969), and OSW Memorandum 91.15 in carrying out these four steps.

Sediment data from automatic or manually-collected samples are used at selected gaging stations to construct a record of daily sediment discharge by using the daily streamflow record. A checklist outlining procedures is used to track progress in data compilation. All records are completed and checked by personnel who have sediment-record experience and who have attended formal training. Deficiencies are discussed with the District Sediment Specialist. Sediment data in computer storage are reviewed during preparation of the annual data report and errors are detected by means of 
verification reviews. The Sediment Specialist approves all updates after they have been reviewed by the designated technician.

The District Sediment Specialist is responsible for ensuring that appropriate procedures for processing sediment data are applied correctly. When the sediment data are being processed for the year, sediment field notes and work sheets for each site are maintained in the District sediment computation folder with the station. After the record has been completed, sediment field notes and work sheets are maintained in the station file.

\section{Sediment Laboratory}

The Wisconsin District does not operate a sediment laboratory. Sediment samples are sent to other selected District sediment laboratories, primarily Iowa and Missouri, for concentration and size analyses.

\section{Sediment Station Analysis}

A sediment station analysis is written for each sediment station operated by the District each water year. The sediment station analysis is a summary of the sediment activities at the station for a given year. The analysis describes the coverage of sampling, the types of samples and sampling, changes that might affect sediment transport or the record, and the methods and reasoning used to compute the record. Information included in the sediment station analysis is presented in a thorough manner, such that the checker and the reviewer can determine from the analysis the adequacy of the activities in defining the record and in accomplishing the objectives defined for the station (OSW Memorandum 91.15).

Current daily sediment records are maintained by personnel computing the station's streamflow record. When the computations have been completed the record is reviewed by either the District Sediment Specialist or a designated technician. Final approval of the station analysis is given by the District Sediment Specialist. After it has been reviewed and approved, the record is backfiled with the station files, which are maintained by the appropriate office.

\section{Sediment Analysis Results}

Concentration and sand-silt size break results from all periodic cross-section suspended-sediment samples and calculated daily mean concentrations for daily sediment stations are published in the District's annual data report. The quality of analytical results is assured by procedures described in quality assurance plans of the laboratories used.

\section{Sediment Data Storage}

Short-term storage of sediment data is maintained by the person analyzing the record. Long-term storage is in the District's or field office files. Copies of graphs, laboratory analyses, and computational sheets are kept with the station files. The field person assigned the station ensures that the files are complete. The person computing the record or the water-quality database manager enters sediment data into the computer database. The Chief, HSDS is responsible for ensuring that appropriate data are included in long-term computer storage. Backfiles are sent to the Federal Records Center (FRC) of the National Archives and Records Administration in Chicago, Ill., approximately every 10 years for long-term storage.

\section{OFFICE SETTING}

Maintaining surface-water data and related information in a systematic and organized manner increases the efficiency and effectiveness of data-analysis and data-dissemination efforts. Good organization of files reduces the likelihood of misplaced information. Misplaced data or field notes can lead to analyses based on inadequate information, and may compromise the quality of analytical results.

This section of the QA Plan describes how station folders, reference maps, level documentation, and other information related to surface-water data are organized and maintained. Additionally, this section provides an overview of how work activities are designed to be carried out within the office setting.

\section{Work Plan}

The structure of the Wisconsin District is such that few individuals work consistently on any one task; most employees involved with the collection, computation, 
or publication of surface-water data in the District also have other significant duties to perform throughout the year as part of other projects. Each employee has a performance work plan which outlines the areas of work

for which the employee is responsible, and criteria that are used to rate the employee's performance each year. Specific workloads are established and adjusted as needed by the Section Chief in consultation with the District Chief. Scheduling conflicts between work on surface-water stations and other work which is part of an employee's work plan are referred first to the Chief, HSDS, or if needed, to the District Chief.

Stations are assigned to field offices or individuals and grouped into field trips which cover a specific portion of the District. Field trips are assigned to individual field personnel who are responsible for all site visits to the stations, as well as periodic review of real-time data to ensure proper instrument operation between site visits. All field personnel are expected to perform all required measurements, maintenance, levels, and minor construction at stations assigned to them. Priority is also given to processing collected data soon after field trips are completed to compute reasonably up-to-date provisional record. It is the responsibility of the Field Office Chief and Section Chief to insure that field personnel have the required office time to do this. Scheduling of site visits is done independently by the individual hydrographer with guidance from the Project Chief and Section Chief. During periods of hydrologic extremes (floods or droughts), or when schedules conflict, site visits may be scheduled by the Field Office Chief, Flood Coordinator, or Section Chief. Each hydrographer is expected to compute completely the records for the stations in his or her field area for the annual data report, and to check the records of other hydrographers as assigned.

\section{File Folders for Surface-Water Stations}

This section of the QA Plan describes the location and makeup of hard-copy files associated with surfacewater data. Information pertaining to files maintained in computer storage can be found in the section titled "Database Management."

For each gaging station, a separate set of file folders is maintained that includes folders for station descriptions, station analyses, shift analysis and stageshift diagrams, ratings (tables and original graphs), measurement summary (Form 9-207), level summary sheet, primary computation sheets, and hydrographs. Backfile folders for previous water years generally are stored alphabetically and separate from the current water-year files. Current file folders are usually arranged in file drawers by downstream order number depending on office preference. Current file folders also contain a checklist for tracking work progress and ensuring that all steps are completed, as well as measurements, shift analysis and stage-shift diagrams, correspondence, newspaper clippings, photographs and any other information needed on a continuing basis for computing the record. Each Field Office is responsible for storing the data for its stations. Measurements are stored in file drawers by station in downstream order, and filed chronologically. Measurements are maintained in the District office indefinitely.

The SW CBR Project Chief maintains a complete set of current station history and backfile folders. Questions about the content and maintenance of current and backfile folders should be directed to the SW CBR Project Chief or Chief, HSDS.

\section{Field-Trip Folders}

Each hydrographer is responsible for maintaining field folders for his or her assigned field-trip area or selected surface-water project study area. The folders contain station descriptions, safety information, station lists, rating and discharge measurement data, sampling instructions, level summary, and other pertinent information for each site. Each group of stations in a field trip is kept in a field file along with a current flood plan, the most recent copy of the data report, and detailed road maps.

\section{Levels}

Recent level notes are included in the current computation folders for each gaging station and are reviewed as part of the record. A summary of levels for each station is also kept in the current station and field folders. A completed front cover sheet that summarizes the results of the level survey and the action taken should be included. After the level notes have been reviewed by a surface-water record reviewer, the notes are backfiled. Historical level notes are located in the District Office but may also be stored in each Field Office where they are retained indefinitely. 


\section{Station Descriptions}

Copies of surface-water station descriptions are maintained in the current station folders located in each Field Office and the District Office. The original descriptions are located in folders and updated electronically. When updates are needed, the station description is changed in the computer and a new date is written on the description. All changes are made to the computer copy and maintained by the District Hydrologic Assistant in a centralized computer directory that is available to District personnel. Discontinued station descriptions are located in the District Office and in each Field Office.

\section{Discontinued Stations}

A discontinued station file is maintained in the District Office. Folders for station descriptions, station analyses, ratings (tables and original graphs), list of measurements (Form 9-207), correspondence, and other important documentation for a station are retained in this discontinued-station file when a station is discontinued. Folders are grouped by station, and the stations are arranged in alphabetical order. The water-year folders are transferred to the Federal Records Center periodically, as needed.

\section{Map Files}

The District Office maintains the official drainagearea map file consisting of a set of 7.5- and 15-minute USGS quadrangle maps for the state on which the drainage areas for all gaging stations and other data-collection sites have been delineated and a station number assigned. These maps are used in conjunction with the completed site record sheets that are stored in the same location. The file is maintained permanently within the District Office and is not to be removed from the office. Almost all of the maps have been digitized and are also available in the GIS data base. A separate file of maps is maintained for field use and work copies. The Hydrologic Assistant, HSDS, is responsible for maintaining the files.

\section{Archiving}

All WRD personnel are directed to safeguard all original field records containing geologic and hydrogeologic measurements and observations. Selected material not maintained in field offices are placed in archival storage. Detailed information on what records have been submitted to archival centers should be retained in the District or project office (WRD Memorandum 77.83). The types of original data that should be archived include, but are not limited to, recorder charts and tapes, original data and edited data, observer's notes and readings, station descriptions, analyses, and other supporting information (WRD Memorandum 99.33 and 92.59; Hubbard, 1992, p. 12). An agreement exists between WRD and the FRC to archive original-data records (memorandum from the Chief, Branch of Operational Support, WRD, May 7, 1993).

Surface-water information is sent to the FRC from the Wisconsin District as needed and according to schedules outlined in the District's File Maintenance and Disposition Plan, and the Plan and Guidance for the Management and Archiving of Hydrologic Data in the Wisconsin District (2000), unpublished document available at the District Office. The HSDS Hydrologic Assistant is responsible for assisting project chiefs in deciding what information is sent to the FRC, for ensuring that the information is properly packed and logged, for ascertaining that the information is received by the FRC, and for retrieving records from the FRC. Records of archived documents are maintained by the hydrologic assistant in a central computerized database. Questions concerning archiving procedures should be addressed to the HSDS Hydrologic Assistant or the District Records Officer. Personnel who receive a request for information that requires accessing archived records should refer the request to the hydrologic assistant. Project Chiefs are responsible for ensuring that appropriate project data and information are archived according to the District's Plan and Guidance for the Management and Archiving of Hydrologic Data.

\section{Communication of New Methods and Current Procedures}

The Field Office Chief will hold in-house on-thejob training sessions as needed to communicate any new methods or procedures related to data-collection activities. Copies of all memorandums from WRD, 
OSW, and OWQ are given to each office and responsible employee. Monthly staff meetings and annual Section meetings are held to pass on new information, provide timely training, resolve questions, and discuss procedures. It is the responsibility of the Chief, HSDS, project chiefs, and Field Office Chiefs to inform others of correct procedures, and the responsibility of all personnel to ask questions if procedures are not clear.

\section{DATABASE MANAGEMENT}

Surface-water data are collected by personnel of the WRD and stored in computer databases. Proper storage and maintenance of surface-water data are critical components in the effective utilization of those data. Because computer hardware and software used to process and store surface-water data are changing continually, descriptions of policies and procedures associated with these functions are quickly outdated. Dealing with recurring periods of transition, in effect, emphasizes the importance of having clearly assigned authority and clearly stated procedures for correctly populating, updating, reviewing, and maintaining a database.

Database management in the District is conducted by a team of individuals for each of the types of data constituting the National Water Information System (NWIS): surface water (ADAPS), ground water (GWSI), and water quality (QWDATA). The HSDS Chief has the final responsibility for ensuring that the surface-water database is current and correct. The HSDS Chief and computer Site Administrator are responsible for ensuring that the latest updates to the NWIS computer programs are loaded and operational on a timely basis and that training in new programs or updates is provided to District personnel. The NWIS Database Manager is responsible for updating the National database in a timely manner and flagging daily values as final after the data have been reviewed and approved for publication.

\section{PUBLICATION OF SURFACE-WATER DATA}

The act of Congress (Organic Act) that created the USGS in 1879 established the agency's obligation to make public the results of its investigations and research and to perform, on a continuing, systematic, and scientific basis, the investigation of the geologic structure, mineral resources, and products of the National domain (Alt and Iseri, 1986, p. 4). Fulfilling this obligation includes the publication of surface-water data and the interpretive information derived from the analyses of surface-water data.

\section{Publication Policy}

The USGS and WRD have created specific policies pertaining to publication of data and interpretation of those data. All WRD personnel, including those of the Wisconsin District, are required to abide by those policies. A brief summary of goals, procedures, and policies are presented in Alt and Iseri (1986, p. 4-37).

All information obtained through investigations and observations by the staff of the USGS or by its contractors must be held confidential and not be disclosed to others until the information is made available to all, impartially and simultaneously, through Directorapproved formal publication or other means of public release, except to the extent that such release is mandated by law (Alt and Iseri, 1986, p. 14). With the approval of the Director, hydrologic measurements resulting from observations and laboratory analyses, after they have been reviewed for accuracy by designated WRD personnel, have been excluded from the requirements to hold unpublished information confidential (Alt and Iseri, 1986, p. 15).

All interpretive writings in which the USGS has a proprietary interest, including abstracts, letters to the editor, and all writings that show the author's title and USGS affiliation, must be approved by the Director before release for publication. The objectives of the Director's review are to provide a final check of the technical quality of the writing and to make certain that it meets USGS publication standards and is consistent with policies of the USGS and U.S. Department of the Interior. Director's approval ensures that each publication or writing is (1) impartial and objective, (2) has conclusions that do not compromise the USGS's official position, (3) does not take an unwarranted advocacy position, and (4) does not criticize or compete with other governmental agencies or the private sector (Hansen, 1991, p. 10).

\section{Types of Publications}

Surface-water data and data analyses are presented in various types of book publications released by the USGS. Publications of the formal series include WaterSupply Papers, Professional Papers, Bulletins, Circu- 
lars, Techniques of Water-Resources Investigations, Special Reports, and Selected Papers in the Hydrologic Sciences (Alt and Iseri, 1986, p. 42). Publications in the informal series include Water-Resources Investigations Reports, Open-File Reports, and Administrative Reports (Alt and Iseri, 1986, p. 52). The USGS also publishes short Fact Sheets on various subjects. Factors considered by Wisconsin District personnel when determining which form of publication is to be used in presenting various types of information are given in Green (1991, p. 14). Data reports are included in the Open-File Report series. Surface-water data collected by this District are published each year in a hydrologic data report that is issued as part of an annual series entitled "U.S. Geological Survey Water-Data Reports."

\section{Preparation of Annual Water-Data Report}

When records computation for the water year has been completed and the data collected and analyzed by District personnel have been determined to be correct and finalized, the surface-water data for that water year are published along with other data in the District's annual data report. The annual data report is part of the series titled "U.S. Geological Survey Water-Data Reports." Information presented in the annual data report includes daily discharge values for the year, extremes for the year and period of record, and various statistics as well as the manuscript station descriptions. Information contained in the manuscript description includes physical descriptions of the station and basin, history of the station and data, and statements of cooperation. In preparing the annual data report for publication, the District follows the guidelines presented in the report, "WRD Data Reports Preparation Guide," (Novak, 1985).

The Data Report Team (Project Chiefs of basic data projects, Hydrologic Assistant, Surface-Water Specialist, and Chief, HSDS) is responsible for preparing the annual data report. The Project Chiefs and Senior Technicians oversee all detailed facets of the data-collection, data-analysis, and report-production process. Final records are received from the Field Office and a District pre-publication review by the senior hydrologic technicians, Project Chief, and Chief, HSDS, is conducted. When the record is approved for publication, the manuscript is updated in the computer and a camera-ready page is prepared and reviewed. A copy of the final printed report is reviewed by the Project Chief and the HSDS Chief. The Chief, HSDS, is responsible for the accuracy of and for overseeing the preparation, review, and publication of the annual data report. The ultimate responsibility for approving the annual data report, however, belongs to the District Chief. The District's goal is to send the camera-ready report to the printer within 6 months after the end of the water year.

\section{Review Process}

Procedures for publication and requirements for manuscript review by WRD are summarized in Hansen (1991, p.36-41) and Alt and Iseri (1986). The Wisconsin District fulfills those requirements for review and approval of reports prior to printing and distribution. All reports written by USGS scientists in connection with their official duties must be approved by the originating Division and the Director or designated representative. At least two technical reviews of each report are required by WRD (Hansen, 1991, p. 36). Competent and thorough editorial and technical review is the most certain way to improve and assure the high quality of the final report (Moore and others, 1990, p. 24-29). Principles of editorial review and responsibilities of reviewers and authors are presented in Moore and others (1990). The annual data reports are not required to receive editorial review. The reports are reviewed for policy and reproducibility (Hansen, 1991, p. 36). In addition to the standard checking and reviewing of the data included in the records-computation process, project chiefs and the Chief, HSDS, are responsible for reviewing the final manuscript and reviewing the proof copy before it is printed. The District Chief or designated representative has been given the authority to approve the annual data report for publication (Alt and Iseri, 1986, p. 129).

\section{SAFETY}

Surface-water activities in the District include making streamflow-discharge measurements during adverse weather and flood conditions. Heavy rain, wind, ice, snow, cold temperatures, and extreme heat can create difficulties in collecting hydrologic data and can expose field personnel to various dangers. Additional attention must be given to safety when working on cableways, from boats, and from highway bridges. Field vehicles must be maintained in a safe condition. Employee safety is the highest priority when collecting hydrologic data. 
A Safety Officer has been designated by the District; his duties include being knowledgeable about the latest safety information, making appropriate employees aware of that information, providing a list of available training courses, tracking training needs and suggesting training for individuals, in some cases conducting training classes, assuring that safety plans are prepared, performing safety inspections, and advising and serving on the District Safety Committee. Each Field Office is responsible for the annual safety inspections of gaging stations and field vehicles; cableways are inspected by trained District inspectors. Questions, concerns, or suggestions for improving safety should be directed to the Safety Officer or Safety Committee.

Performing work activities in a manner that ensures the safety of personnel and others is the highest priority of the USGS and the Wisconsin District. Beyond the obvious adverse effects, such as accidents and personal injuries, that unsafe conditions can have on personnel, they also can have a direct effect on the quality of surface-water data and data analysis. For example, errors may be made when an individual's attention to detail is compromised when dangerous conditions create distractions. So that employees are aware of and follow established procedures and policies that promote all aspects of safety, the District Safety Officer communicates information and directives related to safety to all personnel by in-house training classes, memorandums, videotapes, and safety literature. Specific policies and procedures related to safety can be found in the USGS Occupational Hazard and Safety Handbook and Internet Safety web site (links from the District home page). All employees must attend scheduled safety training, read safety memorandums, and follow all safety procedures.

\section{TRAINING}

Ensuring that personnel obtain knowledge of correct methods and procedures is a vital aspect of maintaining the quality of surface-water data and data analysis. The District improves the quality of work and eliminates the source of many potential errors by providing appropriate training to personnel. The Wisconsin District has a Training Officer who ensures that all employees are aware of available training opportunities and who prepares an annual District training plan. The District also has prepared a new-employee Orientation Guide and a Training Guide that are given to each employee for his or her use. The training guide describes ways to obtain training, training procedures, and management alternatives to training. Employees and their supervisors are required to design an Individual Development Plan annually during the performance appraisal interview. Employees and supervisors discuss both short-term and long-term training needs and document these needs. Supervisors furnish copies of the training-needs documentation to the Training Officer, who compiles the information in the District training plan. The USGS provides a variety of training opportunities including on-the-job training, courses offered at the USGS National Training Center, courses at local colleges and universities, training provided by other agencies and organizations, videos, and on-line courses. Other training materials for employee reference include the TWRI report series and technical memorandums.

\section{SUMMARY}

Surface-water activities in the Wisconsin District are part of the Water Resources Division's overall mission of appraising the quantity and quality of the Nation's water resources. Streamflow data are part of the water-resources information used for hydroelectric power generation, reservoir management, floodplain management, wastewater treatment, water supply, and a host of other water-management and water-resources planning activities.

This Surface-Water Quality-Assurance Plan documents the policies and procedures followed by the Wisconsin District of the USGS, WRD, in the collection, processing, storage, analysis, and publication of surface-water data. Specific types of surface-water data discussed in this report include stage, streamflow, and sediment. Office procedures include descriptions of the organization, maintenance, and archiving of information related to surface-water data. Procedures for management of the computer database emphasize the proper storage and maintenance of surface-water data to maximize the accuracy and effective use of those data. Publication of surface-water data is described in terms of policy, types of publications, manuscript preparation, and the manuscript-review process. The responsibilities of District personnel for implementation of quality assurance are described throughout so that each employee is aware of his or her role. The plan describes the system of quality control used by the Water Resources Division and highlights the importance of providing high-quality products to the users of USGS data. 


\section{REFERENCES CITED}

Alt, D.W., and Iseri, K.T., 1986, Water Resources Division publications guide: Volume I, Publications policy and text preparation: U.S. Geological Survey Report, 429 p.

Arcement, G.J., and Schneider, V.R., 1989, Guide for selecting Manning's roughness coefficients for natural channels and flood plains: U.S. Geological Survey WaterSupply Paper 2339, 38 p.

Barnes, H.B, 1967, Roughness characteristics of natural channels: U.S. Geological Survey Water-Supply Paper $1849,213 \mathrm{p}$.

Benson, M.A., and Dalrymple, Tate, 1967, General field and office procedures for indirect discharge measurements: U.S. Geological Survey Techniques of Water-Resources Investigations, book 3, chap. A1, $30 \mathrm{p}$.

Bodhaine, G.L., 1982, Measurement of peak discharge at culverts by indirect methods: U.S. Geological Survey Techniques of Water-Resources Investigations, book 3, chap. A3, $60 \mathrm{p}$.

Brunner, G.W., 2001, HEC-RAS, River Analysis Systems user's manual: U.S. Army Corps of Engineers, Hydrologic Engineering Center (HEC), Report CPD-68, 320 p.

Buchanan, T.J., and Somers, W.P., 1969, Discharge measurements at gaging stations: U.S. Geological Survey Techniques of Water-Resources Investigations, book 3 , chap. A8, 65 p.

Carter, R.W., and Davidian, Jacob, 1968, General procedures for gaging streams: U.S. Geological Survey Techniques of Water-Resources Investigations, book 3, chap. A6, $13 \mathrm{p}$.

Coons, W.F., 1995, Estimates of roughness coefficients for selected natural stream channels with vegetated banks in New York: U.S. Geological Survey Open-File Report 93-161, 133 p.

Dalrymple, Tate, and Benson, M.A., 1967, Measurement of peak discharge by the slope-area method: U.S. Geological Survey Techniques of Water-Resources Investigations, book 3, chap. A2, 12 p.

Davidian, Jacob, 1984, Computation of water-surface profiles in open channels: U.S. Geological Survey Techniques of Water-Resources Investigations, book 3 , chap. A15, 48 p.

Edwards, T.K., and Glysson, G.D., 1988, Field methods for measurement of fluvial sediment: U.S. Geological Survey Open-File Report 86-531, 118 p.

Edwards,T.K., and Glysson, G.D., 1999, Field methods for measurement of fluvial sediment: U.S. Geological Survey Techniques of Water-Resources Investigations, book 3, chap. C2, 89 p.

Fulford, J.M., 1997, User's guide to the U.S. Geological Survey Culvert Analysis Program, version 97-08: U.S.
Geological Survey Water-Resources Investigations Report 98-4166, $70 \mathrm{p}$.

Fulford, J.M., 1994, User's guide to SAC, a computer program for computing discharge by slope-area method: U.S. Geological Survey Open-File Report 94-360, 31 p.

Green, J.H., 1991, WRD project and report management guide: U.S. Geological Survey Open-File Report 91-224, $152 \mathrm{p}$.

Guy, H.P., 1969, Laboratory theory and methods for sediment analysis: U.S. Geological Survey Techniques of WaterResources Investigations, book 5, chap. C1, 58 p.

Guy, H.P., 1970, Fluvial sediment concepts: U.S. Geological Survey Techniques of Water-Resources Investigations, book 3, chap. C1, 55 p.

Hansen, W.R., 1991, Suggestions to authors of the reports of the United States Geological Survey, (7th ed): U.S. Geological Survey, $289 \mathrm{p}$.

Hubbard, E.F., 1992, Policy recommendations for management and retention of hydrologic data of the U.S. Geological Survey: U.S. Geological Survey Open-File Report 92-56, 32 p.

Kennedy, E.J., 1983, Computation of continuous records of streamflow: U.S. Geological Survey Techniques of Water-Resources Investigations, book 3, chap. A13, $53 \mathrm{p}$.

1984, Discharge ratings at gaging stations: U.S. Geological Survey Techniques of Water-Resources Investigations, book 3, chap. A10, 59 p.

1990, Levels at streamflow gaging stations: U.S. Geological Survey Techniques of Water-Resources Investigations, book 3 , chap. A19, $31 \mathrm{p}$.

Kilpatrick, F.A., and Schneider, V.R., 1983, Use of flumes in measuring discharge: U.S. Geological Survey Techniques of Water-Resources Investigations, book 3 , chap. A14, 46 p.

Knott, J.M., Glysson, G.D., Malo, B.A., and Schroder, L.J., 1993, Quality assurance plan for the collection and processing of sediment data by the U.S. Geological Survey, Water Resources Division: U.S. Geological Survey Open-File Report 92-499, 18 p.

Knott, J.M., Sholar, C.J., and Matthes, W.J., 1992, Quality assurance guidelines for the analysis of sediment concentration by the U.S. Geological Survey sediment laboratories: U.S. Geological Survey Open-File Report 92-33, $22 \mathrm{p}$.

Matthai, H.F., 1967, Measurement of peak discharge at width contractions by indirect methods: U.S. Geological Survey Techniques of Water-Resources Investigations, book 3, chap. A4, 44 p. 
Moore, J.E, Aronson, D.A., Green, J.H., and Puente, Celso, 1990, Report planning, preparation, and review guide: U.S. Geological Survey Open-File Report 89-275, 81 p.

Novak, C.E., 1985, WRD data reports preparation guide, U.S. Geological Survey, Water-Resources Division, 199 p.

Porterfield, George, 1972, Computation of fluvial-sediment discharge: U.S. Geological Survey Techniques of WaterResources Investigations, book 3, chap. C3, 66 p.

Rantz, S.E., and others, 1982, Measurements and computation of streamflow, volumes 1 and 2: U.S. Geological Survey Water-Supply Paper 2175, 631 p.

Sauer, V.B., and Meyer, R.W., 1992, Determination of errors in individual discharge measurements: U.S. Geological Survey Open-File Report 92-144, 21 p.
Schroder, L.J., and Shampine, W.J., 1992, Guidelines for preparing a quality assurance plan for the district offices of the U.S. Geological Survey: U.S. Geological Survey Open-File Report 92-136, 14 p.

Shearman, J.O., 1990, User's manual for WSPRO-A computer model for water surface profile computations: U.S. Federal Highway Administration Report, FHWA-IP$89-027,187 \mathrm{p}$.

Smoot, G.F., and Novak, C.E., 1968, Calibration and maintenance of vertical-axis type current meters: U.S. Geological Survey Techniques of Water-Resources Investigations, book 8 , chap. B2, 15 p. 
APPENDIXES 


\section{Appendix 1. Water Resources Division, Office of Surface Water, and Office of Water Quality Memorandums}

The following memorandums are available in the Wisconsin District Office and also are available on the USGS Internet web site (http://water.usgs.gov/admin/memo).

\section{Water Resources Division}

Memorandum

number

\section{$\underline{\text { Subject }}$}

00.12 Policy and guidelines for documentation and reporting of flood events.

99.34 Quality assurance measures for serving real-time water data on the World Wide Web.

99.33 Preservation of original digital field-recorded time-series data.

95.19 Policy for Making Provisional Water-Resource Data Available on the Internet.

92.59 Policy for management and retention of hydrologic data of the U.S. Geological Survey.

85.129 Publication of furnished streamflow data.

$77.83 \quad$ Retention of original water records.

\section{Office of Surface Water}

Memorandum

number

$\underline{\text { Subject }}$

2002.03

Release of WinRiver Software for computing streamflow from acoustic profiler data.

2002.02

Policy and technical guidance on discharge measurements using acoustic doppler current profilers.

2002.01

Configuration of acoustic profilers ( $\mathrm{RD}$ instruments) for measurement of streamflow.

99.06

Care and maintenance of vertical-axis current meters.

99.05 Development of new standard rating tables for the Price Type AA and pygmy current meters.

96.05 Policy concerning accuracy of stage data.

93.12 TWRI Book 3, Chap. A19-Clarification of leveling procedure (See Kennedy, 1990).

93.07 Policy statement on stage accuracy.

93.01 Summary of documentation that describes instrumentation and field methods for collecting sediment data.

92.10 Guidelines for identifying and evaluating peak-discharge errors.

92.09 Adjustment of discharge measurements made at a distance from the gaging station during periods of changing stage and discharge.

92.08 Compilation of memorandums related to sediment. 
92.04 In reply refer to: November 20, 1991.

91.15 PROGRAMS AND PLANS—Guidelines for the analyses of sediment data.

90.08 HISTORICAL BACKGROUND.

90.01 EQUIPMENT AND SUPPLIES-Polymer current-meter rotors.

89.07 Policy to ensure the accurate performance of current meters.

88.18 EQUIPMENT AND SUPPLIES-Winter equipment.

88.07 Guidelines for the operation of a crest-stage program.

87.05 PUBLICATIONS-Bridge waterways analysis: Research report (see Shearman and others, 1986).

PROGRAMS AND PLANS-Policy providing low-flow information.

85.07 EQUIPMENT AND SUPPLIES-Current meters.

84.05

Equipment for the measurement of flow under ice.

\section{Office of Water Ouality}

Memorandum number

$\underline{\text { Subject }}$

80.17 New sample splitter for water-quality samples.

76.17 Sampling mixtures of water and suspended sediment in streams.

\section{Branch of Operational Support}

Unnumbered, Disposition of original hydrologic records. dated 5/7/93 


\section{Appendix 2. Computer Procedures for Processing Real-Time Data}

\section{By W.R. Krug}

The following is the "READ.ME" file from /archive21/ directory on the SUN computer which outlines the procedures used to process the REALTIME data. Note the section about e-mail sent to report potential errors. There is also a file, generated three times each day, that summarizes the errors encountered by DECODES in processing the data; these are normally unexpected gaps in the data. The database manager keeps a close watch on these files, finds reasons for the errors, and corrects them, if possible. Error files may be see in, for example, /archive21/sum.err.010806 (new ones are created for each day, and about 1 week's worth remain in the directory).

\section{DATA PATH AND PROGRAMS FOR DATALOGGER RETRIEVALS}

file: /archive21/READ.ME

FOR DATA FILES FROM LAPTOPS/FLOPPYS:

For all of the files ending with .DUMP in /var/ftp/incoming/.cr21 on sundwimdn, there is a job run by sundwimdn "NWIS" every hour (on the hour). This job performs two functions. First, it copies the dump file to /archive21 (if a file with the same name already exists, it will rename the file to SITENAME.YYMMDD.1.DUMP (or .2.DUMP, or .3.DUMP, etc.) to keep from overwriting files.) The second function is to " $\mathrm{mv}$ " the files to /usr/opt/nwis/decodes/satin/wiedl/. From there SATIN and SENTRY take care of running DECODES, loading the files into ADAPS, and running primaries.

A running log is kept in /tmp/mv.dump.log for each successful operation.

\section{FOR FILES RETRIEVED AUTOMATICALLY}

4:35 7:05 9:35 AM 12:05 PM 2:35 PM 5:05 PM \& 7:35 PM Each day a program is run by "NWIS" from sundwimdn, to process the data files put into /archive21/INCOMING/ by the pc208 program. It runs continuously over a 2-hour period. This script is /archive21/scripts/dump.to.satin.ksh. At 12:05 AM a slight variation (/archive21/scripts/dump.to.satin.short.ksh) is run. It runs for only 1 hour. Both of these programs add the header and trailer lines required by DECODES, and copy the results to files named like: SITENAME.yymmdd.DUMP. 
They then rename the original files, with names like: SITENAME.DAT to SITENAME.DAT.1. The information for the header lines is extracted from /archive21/devices.rdb.

See the "FILE PATH" section below for more details.

The program takes the /archive/INCOMMN/station.dat files that are available and processes them. If it finds no such files, it will wait 10 minutes and try again. If it finds only $1,2,3$, or 4 it will wait 5 minutes to make sure the retrievals are finished, then process them. If it finds more than four, it will process all but the last four (which might still be being retrieved).

This program also includes running /archive21/scripts/no.dupes to eliminate duplicate time lines, or time that regresses. It will also change 0.000 midnights to 0000 . Processed files will be stored in /archive21//NCOMING/good, and any changes made will be stored in /archive21/INCOMING/junk. A summary of odd time gaps will be in

/archive21/INCOMTNG/gap.summary.yymmdd.

As the processing of each station is finished, the raw data (plus header and /END) in STATrON.yymmdd.DUMP are moved to the /archive21 directory. From there they will be archived to individual station directories about midnight. The "good" data file is copied from the /archive21/INCOMING/good/ directory to /usr/opt/nwis/decodes/satin/wiedl/directory. SATIN will pick it up from there.

\section{DATA TO NWISWEB:}

New data are relayed from ADAPS to NWISWEB every 15 minutes as they are put into ADAPS.

Whenever data arrive from ADAPS, the Web page is updated.

\section{MISCELLANEOUS CLEANUP AND CHECKING}

4:15 AM \& PM: /archive21/scripts/get.dcp is run by NWIS on sundwimdn, to get data for several DCP sites from the Corps of Engineers web site. Afton is sent through SATIN/SENTRY as backup data.

5:05 AM: /archive21/scripts/sendbadval.ksh is run by NWIS on sundwimdn, to send notice to dwowens and wrkrug whenever Badger Mill at Verona has a bad value $(-6999)$ in the output. 
5:55 AM (Monday): /archive21/scripts/sendtime.ksh is run by NWIS on sundwimdn, to check the time of the last values in the STATION.dat.1 files against the time of the file. It e-mails a summary of possible problems to Bill Krug.

6:25 AM: /archive21/scripts/sendbat.all.ksh is run by NWIS on sundwimdn, to check the battery voltage and tank pressure returned on the "midnight" lines of data retrievals. It searches the /archive21/incoming/STATION.dat.1 files. If low voltage is found, e-mail is sent to the person responsible. (e-mail names are embedded in the ksh script). 6:25 AM Each day, sundwimdn "NWIS" runs a job to produce the "daily.retrievals" files in the direc-

tory/archive21/daily.retrieval. A slightly different version is run on weekends so that the output includes the whole weekend until Monday.

6:30 AM: A program is run by NWIS from sundwimdn, to send the daily retrievals for Appleton and Oshkosh to the Detroit U.S. Army Corps of Engineers office, using /archive21/scripts/sendcorps.ksh.

6:37 AM: A program is run by NWISWEB from webdwimdn, to send e-mail to staff interested in current rainfall, summarizing the rain reported by dataloggers in the past 24 hours. $/ \mathrm{log} /$ sutil/check.rain.ksh

6:45 AM: A program is run by NWISWEB on webdwimdn to send e-mail to field people listing warning flags about rapid stage changes, and other warning flags. /log/sutil/check.errcode.ksh

6:55 AM \& PM NWISWEB on webdwimdn runs/log/sutil/check.flood.ksh to send e-mail to rjwaschb, wrkrug, and field people if there are any NWISWEB stations at or near flood stage.

7:00 AM: A program is run by NWISWEB on webdwimdn to send e-mail to Jeff Steve at MMSD with the mean and range of all data collected the previous day at the Badger Mill Creek site near Verona. /log/sutil/badger.temp.ksh 7:05 AM: A program is run by NWISWEB on webdwimdn to send e-mail to field people about samples taken. /log/sutil/check.sample.ksh

8:50, 13:50, and 21:50: /archive21/scripts/check.cr21 is run by NWIS from sundwimdn. This job remotely checks NWISWEB, and creates a summary list of all sites in NWISWEB page that have not been updated today. This is stored as /archive21/check.cr21.log.

8:59, 13:59, and 21:59: (Nine minutes later.) /archive21/scripts/check.sum.ksh is run the same way. This runs DECODES on all of the sites, using the data in /archive21/NNCOMING/good/SITENAME.yymmdd.DUMP files to 
produce "sum" files (the std files are discarded). The full sum files are in /archive21/NNCOMING/good/sum.all, and a more useful summary is stored in /archive21/check.cr21.log. The script writes the summary to /archive21/sum.err.yymmdd.

8:30 AM 10:30 AM 12:30 PM 2:30 PM 4:30 PM Each day a program is run by NWIS from sundwimdn, /archive21/scripts/sum.log.ksh, extracts useful data from /archive21/pc208w/working/swf $\$ . \log$ and swf $\$ 2 . \log$, and appends it to a file named err.log located in the directory for each site: /archive21/ACTIVE/sitename. The old swf $\$ . \log$ is renamed swf.log.yymmdd, to preserve it. An e-mail summary is sent to alert people of failures.

8:38 AM: (Monday) /archive21/scripts/clock.check.ksh is run by NWIS from sundwimdn, to scan the err.log files for each site, looking for the last clock check, and e-mailing about any sites more than a minute or so off.

0:08 AM: a clean-up job is run by NWIS from sundwimdn. This is /archive21/scripts/subdirall.ksh, which converts all the files named SITEFILE.yymmdd.DUMP to lower case, and copies them down to the directories: /archive21/ACTIVE/sitename/. In the process, the "sitename" is removed from the filename. A log of this action is kept in: /archive21/subdir.log. The program also removes /archive21/sum.err.yymmdd files more than 7 days old (moving them to /gary/reston/decodes for archiving). [The move is temporarily suspended, until /gary is mounted on sundwimdn 10/13/99.]

0:18 AM (Tuesday \& Friday): /archive21/scripts/subdir-a.ksh is run by nwis on sundwimdn, to take care of any "old" SITEFILE.yymmdd.DUMP files that might have appeared in /archive21. It is similar to subdirall.ksh, but has a different date function.

EMAIL SENT

6:15 AM /archive21/scripts/senderr.ksh

To dwowens, wrkrug: from /archive21/PC208/swf\$.log, all lines with F or W (Failures of calls or Warnings) 5:55 AM /archive21/scripts/sendtime.ksh (Monday only)

To wrkrug: List of dataloggers where the time of the retrieval does not agree well with last time in file.

6:05 AM /archive21/scripts/sendbat.all.ksh 
To wrkrug, dwowens, rjwaschb [and to appropriate project chiefs or field office]: Voltage from midnight output line from datalogger, IF voltage of datalogger battery $<12.3$, or minimum voltage of cell phone battery $<12.2$ volts OR low pressure if below 500 at selected sites.

6:30 AM /archive21/scripts/sendcorps.ksh

To: David.N.Barilovich@usace.army.mil: Appleton \& Oshkosh daily.retrieval files for Detroit Corps of Engineers.

7:00 AM /home/wrkrug/sbin/check.dat

To: wrkrug Lists /archive21/NNCOMING/*.dat.1 files that have not been updated "today." Lists /archive21/INCOMING/*.dat files that remain unprocessed.

7:00 AM /log/sutil/badger.temp.ksh

To: jeffs@madsewer.org: Min, Max, and Mean of Stage, Discharge and Water Temperature at Badger Mill Creek for the previous calendar day.

7:05 AM /log/sutil/check.sample.ksh

To: Field people responsible for samplers: Data on the time and gage height of recent samples.

FILES TO BE MAINTAINED

[SEE ALSO file /archive21/CREATING.NEW.SITES]

There are numerous files to be maintained to keep this system functioning.

/archive21/devices.rdb

This is an rdb file (tab delimited). The fields are as follows:

1. Station number

2. Station Name (upper case, as used on SUN directory names)

3. Station Name (lower case, same as \#2 otherwise)

4. 8-character station name (as used on PC tcom)

5. Device type, and sequence number (for DECODES)

6. Text labelling data in columns of datalogger output.

e.g. 04=STAGE,05=CUML_RAINFALL 
/archive21/scripts/sum.log.ksh

This script now gets its list of station names from /archive21/devices.rdb.

This script is a loop that will "do" some actions for all sites in a list. This list has first letters capitalized, and contains the names of the sites as found in the /archive21/PC208/swf $\$ . \log$ file. /archive21/ACTIVE/sitename"/wy01 (or the last 2 digits of current year)

When a new station is started, the subdirectory under/archive21/ACTIVE/ must be created for it. In addition, a subdirectory should be created under it, called wy01. The subdirectory name should be the same as field \#3 in /archive21/devices.rdb.

\section{FILE PATH}

This file is designed to show the data path through the "realtime" data network on the DG.

For filenames, we will use the date of April 15, 1999 (990415) and the imaginary river: 04050607 Middle River near Centerville, WI

The naming convention on the DG (carried over from the PRIME) is to use the city name (if possible) in UPPER CASE, until the archiving step.

The PC208 program, which makes the phone calls is limited to [8-characters].[3-characters] like old PCs. So the name is truncated to the first 8 characters: "centervi".

PC208 writes the raw data dump to: centervi.dat in the directory: /archive21/incoming/ The program on the DG that processes this file is called /archive21/scripts/dump.to.satin.ksh, and it produces at least 4 , and sometimes 5 , output files:

(1) /archive21/incoming/centervi.dat.1

(2) /archive21/incoming/good/CENTERVILLE.990415.DUMP

(3) /usr/opt/decodes/satin/wiedl/EDL.CENTERVILLE.990415.TRANS

(4) /archive21/CENTERVILLE.990415.DUMP and possibly:

(5) /archive2 1/incoming/junk/CENTERVILLE.990415.removed 
For files (2) through (5), if the file of that name already exists, "990415.1" will be used instead of "990415". If “990415.1" already exists, "990415.2" will be used instead, etc. This keeps the system from overwriting and destroying good data.

EXPLANATION OF FILES (1) THROUGH (5)

(1) /archive21/incoming/centervi.dat.1

This is an exact copy of /archive21/incoming/centervi.dat and is overwritten each time. Its only purpose is for checking what is going on with the system.

(2) /archive21/incoming/good/CENTERVILLE.990415.DUMP

This file has the "good" data from /archive21/incoming/centervi.dat. A program called "no.dupes" has eliminated any lines with duplicate times, and any lines with times that do not increase from the time of the previous lines.

Any lines removed are stored in:

(5) /archive21/incoming/junk/CENTERVILLE.990415.removed

BOTH OF THESE FILES ARE DELETED AFTER 7 DAYS!

/archive21/incoming/good/CENTERVILLE.990415.DUMP also has header lines added to identify it to DECODES.

//SOURCE DWIMDN EDL

//STATION 04050607

IIDEVICE CR10-1

IDATA

04=STAGE,05=CUML_RAINFALL,06=SMP_CODE

and a line is added to mark the end of the file:

$/ / E N D$

/archive21/incoming/good/CENTERVILLE.990415.DUMP is copied to the next file:

(3) /ust/opt/decodes/satin/wiedl/EDL.CENTERVILLE.990415.TRANS 
This file is the one that SATIN reads and uses as input to DECODES. The file is deleted after SATIN is done with it, and the data is sent to ADAPS.

(4) /archive21/CENTERVILLE.990415.DUMP

This file is a copy of the original (1)/archive21/incoming/centervi.dat.1 with the same "header" lines added. It is the file used for archiving. It has all of the datalines from the original file: good or bad.

(5) /archive21/incoming/junk/CENTERVILLE.990415.removed

This file contains any "bad" lines removed by "no.dupes." It will remain for 7 days, to allow checking of data with "bad" dates/times, and possible correction. After 7 days, the archived file could still be used to make corrections.

\section{NEXT STEP - ARCHIVING:}

An archiving program called /archive21/scripts/subdirall.ksh runs about midnight each night, and takes the files for all stations, like: (4) /archive21/CENTERVILLE.990415.DUMP and archives them to separate subdirectories for each station. This particular file will be moved to: /archive21/active/CENTERVILLE/990415.DUMP After the water year is over, and the annual data report is published, this file will be moved again to: /archive21/active/CENTERVILLE/wy99/990415.DUMP

This is a manual operation.

Eventually, if this station has been discontinued for more than a year, it will be moved again to: /archive21/inactive/CENTERVILLE/wy99/990415.DUMP

Previous water years of the archived files are compressed with "gzip" to save disk space. 


\section{DATAPATH FOR DATALOGGER DATA IN FLOWCHART FORM}

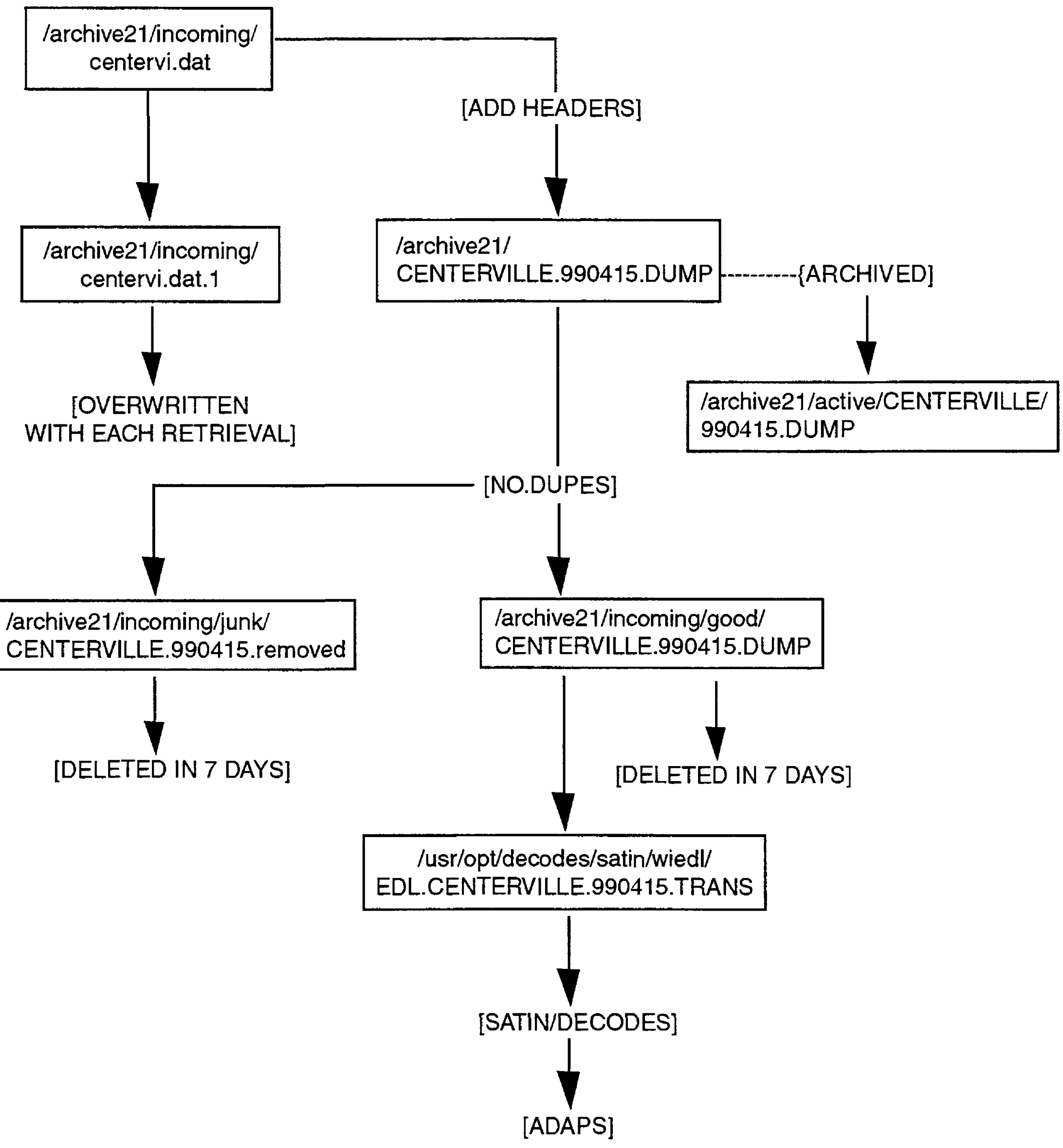

